This document was prepared in conjunction with work accomplished under Contract No. DE-AC09-96SR18500 with the U. S. Department of Energy.

\title{
DISCLAIMER
}

This report was prepared as an account of work sponsored by an agency of the United States Government. Neither the United States Government nor any agency thereof, nor any of their employees, nor any of their contractors, subcontractors or their employees, makes any warranty, express or implied, or assumes any legal liability or responsibility for the accuracy, completeness, or any third party's use or the results of such use of any information, apparatus, product, or process disclosed, or represents that its use would not infringe privately owned rights. Reference herein to any specific commercial product, process, or service by trade name, trademark, manufacturer, or otherwise, does not necessarily constitute or imply its endorsement, recommendation, or favoring by the United States Government or any agency thereof or its contractors or subcontractors. The views and opinions of authors expressed herein do not necessarily state or reflect those of the United States Government or any agency thereof. 
WSRC-TR-2004-00456

Revision: 0

\section{MICROSTRUCTURAL STUDY OF FUSION WELDS IN 304L AND 21Cr-6Ni-9Mn STAINLESS STEELS (U)}

By:

M. H. Tosten

M. J. Morgan

March 2005

Westinghouse Savannah River Company

Savannah River Site

Aiken, South Carolina 29808

Prepared for the U.S. Department of Energy

Under Contract DE-AC09-96SR18500

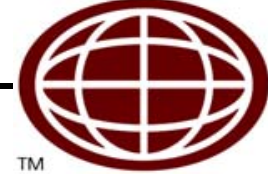




\title{
MICROSTRUCTURAL STUDY OF FUSION WELDS IN 304L AND 21Cr-6Ni-9Mn STAINLESS STEELS (U)
}

\author{
By: \\ M. H. Tosten \\ M. J. Morgan \\ Westinghouse Savannah River Company \\ Savannah River National Laboratory \\ Aiken, SC 29808
}

\begin{abstract}
Light-optical and transmission electron microscopy (TEM) have been employed to characterize the microstructures of a series of fusion welds made on 304L and 21-6-9 stainless steels. The materials investigated in this study included high-energy-rate-forged 304L, conventionally forged 21-6-9, and 304L weld critical plate (higher ferrite potential). The weld critical plate contained an electron beam weld (no filler wire) while other specimens were welded with various combinations of 308L, 309L modified (MOD) and 312 MOD stainless steel filler wires to produce samples with a range of delta $(\delta)$ ferrite contents (4 to 33\%) in the resulting welds. TEM specimens were prepared from broken arc-shaped, mechanical property test specimens that had been used to measure fracture toughness of the fusion welds. Specimens were prepared from regions of the weld heat-affected zones as well as from areas within the weld metal, including areas close to the fracture surface (plastically deformed regions). The observed microstructures varied according to the amount of $\delta$ ferrite in each weld. At the lowest ferrite levels the microstructure consisted of austenite and skeletal $\delta$ ferrite with austenite being the majority (matrix) phase. At intermediate levels of ferrite, lathy austenite/ferrite was observed and the ferrite became continuous throughout the specimens examined. In the weld with the most ferrite, many austenite morphologies were observed and ferrite was the matrix phase. Closest to the fracture surface an increase in dislocation density in both the ferrite and austenite were observed in all welds. Deformation twinning was also observed in the austenite. Many of the welds contained a large number of non-metallic inclusions (oxide particles) which most likely originated from impurities in the weld wires.
\end{abstract}




\section{TABLE OF CONTENTS}

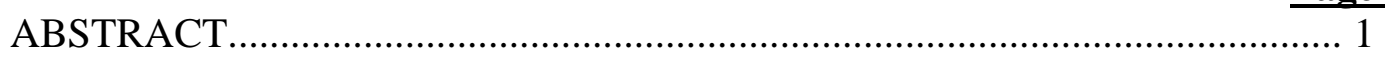

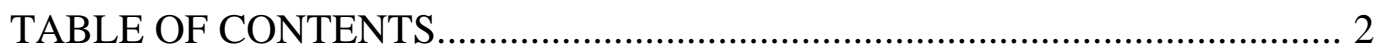

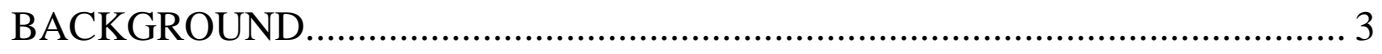

EXPERIMENTAL PROCEDURE................................................................ 4

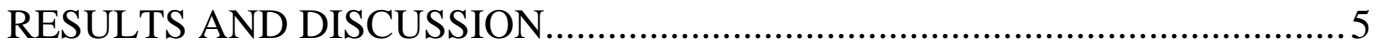

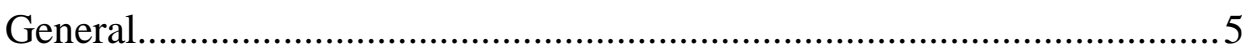

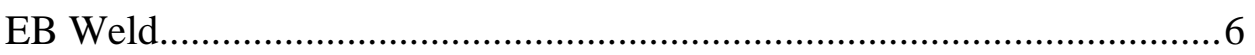

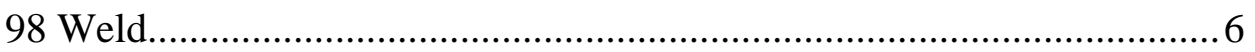

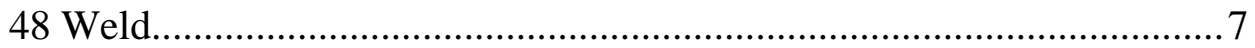

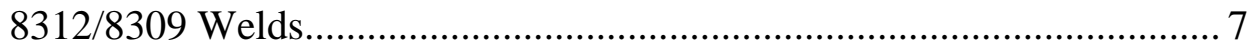

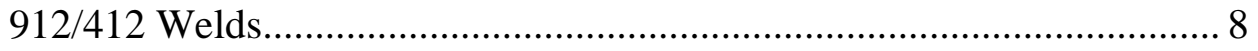

49 Weld................................................................................. 8

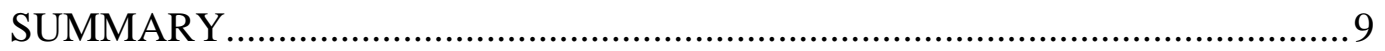

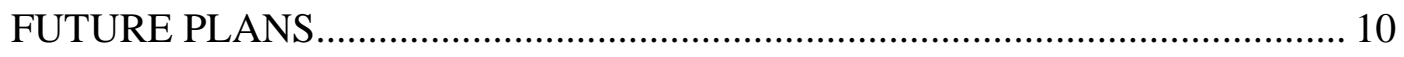

ACKNOWLEDGEMENTS............................................................................10

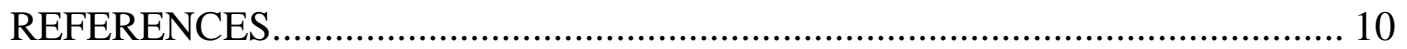

TABLES

1. Compositions and $\mathrm{Cr}_{\mathrm{eq}} / \mathrm{Ni}_{\mathrm{eq}}$ ratios of Materials Used................................12

2. Fusion Welds..............................................................................................13

\section{FIGURES}

1. Images of a 3.125" diameter 304L HERF forging.........................................14

2. Type of fracture toughness specimen machined from forgings......................15

3. Schematic diagram illustrating the sectioning procedure...............................16

4. Skeletal ferrite in EB weld on 304L weld-critical plate.................................17

5. Microstructure of 98 weld-308L wire/21-6-9 conventional forging............. 18

6. Microstructure of 48 weld-308L wire/304L HERF forging...........................20

7. Microstructure of 8312 weld-308L\&312 MOD wires/weld critical plate... 21

8. Microstructure of 8309 weld-308L\&309L MOD wires/weld critical plate. 22

9. Microstructure of 912 weld-312 MOD wire/21-6-9 conventional forging.. 23

10. Microstructure of 412 weld-312 MOD wire/304L HERF forging................24

11. Microstructure of 49 weld-309L MOD wire/304L HERF forging............... 25

12. The WRC-1992 diagram........................................................................... 27 


\section{BACKGROUND}

Stainless steels are the materials of construction for tritium containment vessels. Many vessels contain fusion welds as part of their design. Work is currently underway at the Savannah River National Laboratory to investigate the hydrogen isotope and decay helium effects on the fracture toughness properties of weldments. It is well known that tritium and decay helium reduce the fracture toughness of austenitic stainless steels [Ref. 1,2] but little is known about their effects on fusion welds. Of particular interest is the role that $\delta$ ferrite phase plays in the fracture process and its relative susceptibility to tritium and helium effects. The ferrite phase is needed to prevent solidification and liquation cracking when welding austenitic stainless steels. The initial part of this program involved testing "clean" materials to establish the baseline fracture toughness properties of welds containing various amounts of $\delta$ ferrite.

The Schaeffler diagram [Ref. 3], DeLong diagram [Ref. 4], and the Weld Research Council (WRC)-1988 [Ref. 5] and WRC-1992 [Ref. 6] diagrams are used to predict the solidification mode in austenitic stainless steels and the amount of $\delta$ ferrite in a weld - an indirect indication of susceptibility to hot cracking. The use of these constitution diagrams requires the determination of $\mathrm{Cr}$ and $\mathrm{Ni}$ equivalents $\left(\mathrm{Cr}_{\mathrm{eq}}\right.$ and $\mathrm{Ni}_{\mathrm{eq}}$, respectively) for any given weld. The WRC-1992 diagram is generally regarded as the most accurate diagram available to date. $\mathrm{The}_{\mathrm{Cr}}$ for this diagram includes contributions from the ferrite formers - Cr, Mo and Nb, whereas the $\mathrm{Ni}_{\text {eq }}$ incorporates the amount of $\mathrm{Ni}, \mathrm{C}, \mathrm{N}$ and $\mathrm{Cu}$ (austenite stabilizers) in the weld metal. This diagram, as well as the others, can be used to predict the dilution effects on solidification mode of dissimilar weld metals.

The more recent diagrams of Delong and WRC use the ferrite number (FN) rather than vol.\% ferrite to specify and determine ferrite content in austenitic stainless steels using the $\mathrm{Cr}_{\mathrm{eq}}$ and $\mathrm{Ni}_{\text {eq. }}$ These diagrams are considered more accurate than the vol.\% ferrite measurement used by Schaeffler. FN is an arbitrary value denoting the ferrite content of austenitic stainless steel weld metal and is accepted as an industry standard [Ref. 7]. FN is measured using magnetic measuring instruments but does not necessarily provide the true vol.\% of ferrite in a weld. At 8-10 FN and below the FN approximately equals the average vol. $\% \delta$ ferrite in a weld but at higher FN an over-estimation of the actual ferrite content can occur. For instance a FN of 100 equals roughly 65 vol. $\% \delta$ ferrite.

The formation of $\delta$ ferrite is very complex resulting in a wide variety of microstructures depending upon the composition of the weld pool, i.e., the $\mathrm{Cr}_{\mathrm{eq}} / \mathrm{Ni}_{\mathrm{eq}}$ ratio, and the solidification rate of the weld. Constituent diagrams, like WRC-1992, provide some indication of what microstructure(s) will develop depending on the $\mathrm{Cr}_{\mathrm{eq}} / \mathrm{Ni}_{\mathrm{eq}}$ ratio of the weld pool and a typical arc welding process cooling rate. Solidification mode boundaries included as part of the constituent diagrams provide a way to predict weld microstructures over a wide range of $\mathrm{Cr}_{\text {eq }} / \mathrm{Ni}_{\text {eq }}$ ratios.

The purpose of the present study was to use transmission electron microscopy (TEM) to characterize the weld microstructures that develop as a function of ferrite content. This information will then be used to help better understand how microstructure affects the fracture toughness properties of the welds. The improved understanding of weld 
microstructures will then be used to better understand the fracture toughness behavior(s) of austenitic stainless steels with weldments containing hydrogen and tritium/helium.

\section{EXPERIMENTAL PROCEDURE}

A series of fusion welds was made on 21-6-9 and 304L cylindrical forgings (Figure 1) and "weld critical" 304L plate. The 21-6-9 forging was made using a conventional forging (CF) process and the 304L forging was produced via high-energy-rate-forging (HERF). Type 308L, 309L MOD (modified for higher ferrite content), and 312 MOD stainless steel filler wires were used to prepare multiple pass welds of different target $\delta$ ferrite contents. (The composition and calculated $\mathrm{Cr}_{\mathrm{eq}}$ and $\mathrm{Ni}_{\mathrm{eq}}$ of the base metals and weld wires are given in Table 1 and the target ferrite contents of the welds are given in Table 2.) V-grooves were machined parallel to the long axis of each forging and filled with multi-pass gas tungsten arc (GTA) welds using the 308L, 309L MOD, and 312 MOD filler wires. Mixtures of 308L/309L MOD and 308L/312 MOD wires were used to prepare welds on the weld critical plate. The mixed wire welds were made by twisting two 308L wires together with either one 309L MOD or one 312 MOD wire. To obtain the minimum FN one, single pass, electron beam (EB) weld was also made on the 304L weld critical plate. The composition of the weld critical plate had been adjusted to increase the ferrite potential for the "rapid" solidification and cooling with EB welding.

All welded samples were radiographed to ensure that welds of acceptable quality were produced. Slices were then cut perpendicular to the direction of welding from each forging/plate. Ferrite measurements were made on each weld using a Fischer Feritscope ${ }^{\circledR}$ MP30. The instrument was calibrated to measure vol.\% ferrite, rather than $F N . \mathrm{Cr}_{\text {eq }} / \mathrm{Ni}_{\text {eq }}$ ratios for the welds investigated in this study are listed in Table 2 and were calculated using the "equivalency" formulae appropriate to the WRC-1992 diagram [Ref. 6]. For all welds, except the autogenous, EB weld, a 35\% dilution of the weld metal by the base metal was assumed in order to account for mixing during welding.

Arc-shaped fracture toughness samples, like that illustrated in Figure 2, were machined from the forgings, each to include a fusion weld. Samples were cut such that the crack plane during mechanical testing would be normal to the forging's circumferential direction and the direction of crack propagation would be in the radial direction. Electrical discharge machining was used to create a notch along the weld centerline followed by the generation of a fatigue precrack to produce a sharp "flaw" at the notch. The arc-shaped samples were mechanically tested to determine their fracture toughness properties. After testing, the samples were heat tinted at $350^{\circ} \mathrm{C}$ for 40 minutes to mark the extent of crack propagation during the test and subsequently broken into two pieces for further analysis.

Metallographic mounts were prepared from one "half" of the arc-shaped samples. Samples for light-optical microscopy were polished and etched with $10 \%$ oxalic acid for $\sim 30$ seconds at 6 Vdc. TEM samples were prepared from similarly welded and tested samples. Figure 3 is a schematic representation illustrating the general methodology of TEM sample preparation. Thin slices were cut from samples beginning at the fracture surface (region of plastic deformation) and continuing back into the weld heat-affected zone and base metal. 
Two $3 \mathrm{~mm}$ diameter disks were punched from each slice. These disks were mechanically ground to approximately $0.1 \mathrm{~mm}$ in thickness. Final thinning to produce electron transparent regions was accomplished using a twin jet electropolisher at a potential of about $35 \mathrm{Vdc}$. The electrolyte was a 5\% perchloric acid/methanol solution cooled to $253 \mathrm{~K}$. All samples were examined at $200 \mathrm{kV}$ using a JEOL 2010 TEM equipped with a Kevex Sigma II microanalysis energy-dispersive X-ray spectroscopy (EDS) system.

\section{RESULTS AND DISCUSSION}

\section{General}

Light-optical and TEM images of the welds examined in this study are shown in Figures 411. Figure 12 is a WRC-1992 constitution diagram superposed with the $\mathrm{Cr}_{\mathrm{eq}} / \mathrm{Ni}_{\mathrm{eq}}$ ratios from the welds made in this study (see Table 2). For all except the EB weld, these values were calculated by weighting the $\mathrm{Cr}_{\mathrm{eq}}$ and $\mathrm{Ni}_{\mathrm{eq}}$ for the weld wire at $65 \%$ of their values and the base metal $\mathrm{Cr}_{\mathrm{eq}}$ and $\mathrm{Ni}_{\mathrm{eq}}$ at $35 \%$. Graphically, this was accomplished using a lever rule approach on an extended WRC-1992 diagram [e.g., Ref. 6]. The $\mathrm{Cr}_{\mathrm{eq}} / \mathrm{Ni}_{\mathrm{eq}}$ ratio calculated for the autogenous, EB weld was simply that of the 304L weld critical base plate. The diagram in Figure 12 also contains solidification mode boundaries [Ref. 5]. These boundaries delineate regions of solidification behavior and provide a way to predict weld microstructure based on $\mathrm{Cr}_{\text {eq }} / \mathrm{Ni}_{\text {eq }}$ ratio and/or FN.

Welds in austenitic stainless steel can solidify as either primary austenite or primary $\delta$ ferrite and upon cooling the $\delta$ ferrite can undergo a solid-state transformation to form austenite. Attempts have been made to characterize the general morphologies of the ferrite retained in the welds [Ref. 8-11]. Typically the morphologies are described as eutectic ferrite, skeletal (or vermicular) ferrite, lathy ferrite and acicular or Widmanstätten austenite. Eutectic ferrite is observed in welds which solidify as primary austenite (low $\mathrm{Cr}_{\text {eq }} / \mathrm{Ni}_{\text {eq }}$ ratio). The ferrite forms in the interdendritic regions from the melt with some transforming to austenite during cooling. These microstructures fall within the AF region of the WRC-1992 diagram (Figure 12). Skeletal ferrite (FA region of the WRC-1992 diagram) is observed in welds of intermediate $\mathrm{Cr}_{\mathrm{eq}} / \mathrm{Ni}_{\mathrm{eq}}$ ratios. This type ferrite is formed in primary ferrite-solidified welds that exhibit peritectic/eutectic behavior during the later stages of cooling. Much of the primary ferrite transforms to austenite leaving some retained ferrite in the cores of the former ferrite dendrites. The ferrite that remains is termed skeletal ferrite. Eutectic ferrite and skeletal ferrite are similar in appearance. Lathy ferrite is typically found in welds which also solidify as primary ferrite (FA region) but at higher $\mathrm{Cr}_{\text {eq }} / \mathrm{Ni}_{\mathrm{eq}}$ ratios than skeletal ferrite welds. In both skeletal and (some) lathy ferrite microstructures the austenite volume fraction increases on cooling by the motion of a pre-existing interface - a diffusion-controlled transformation [Ref. 9,11]. Welds at the highest $\mathrm{Cr}_{\mathrm{eq}} / \mathrm{Ni}_{\mathrm{eq}}$ ratios (F region in Figure 12) can solidify as single phase ferrite and may contain acicular or Widmanstätten austenite. A Widmanstätten pattern is produced by groups of parallel austenite/ferrite lamellae intersecting each other at various angles. In this type weld, the austenite forms by the nucleation and growth from single phase ferrite [Ref. 11]. Skeletal and lathy ferrite can also exist in welds that solidify as single phase ferrite. 
EB Weld $-4 \% \delta$ ferrite

This autogenous weld was made on 304L weld critical plate and was chosen as part of the experimental matrix to produce a weld microstructure that contained a low volume fraction of $\delta$ ferrite. Reference to Table 2 and Figure 12 shows that the $\mathrm{Cr}_{\mathrm{eq}} / \mathrm{Ni}_{\mathrm{eq}}$ ratio of 1.56 puts this weld well within the FA region of the diagram and the measured vol.\% ferrite of $4 \%$ coincides with a 4 FN. Light-optical images of this weld are shown in Figures 4(a) and (b). These images show a discontinuous network of skeletal $\delta$ ferrite (as opposed to eutectic ferrite) in an austenitic matrix. TEM images from regions within the weld metal revealed regions of equiaxed austenite grains (Figure 4(c)) containing a low number density of dislocations. Some grains contained subgrain boundaries (Figure 4(d)) which formed as the weld cooled. Only a small amount of $\delta$ ferrite was observed in the TEM foils. Figure 4(e) shows a $\delta$ "grain" in the austenite matrix. This small "grain" is most likely a truncated section of retained $\delta$ ferrite located at the core of an original, primary ferrite dendrite. Few, if any, dislocations were observed in the $\delta$ ferrite in regions removed from the area close to the fracture surface of the test specimen. However, in the plastically deformed regions close to the fracture surface (Figure 4(f)), dislocations were more prevalent in both the austenite and ferrite and, in many areas, deformation twins and stacking faults were observed in the austenite.

\section{$\underline{98 \text { Weld }-5 \% \delta \text { ferrite }}$}

The 98 weld was made using 308L filler wire on a 21-6-9 conventionally forged cylindrical forging. This weld produced a measured ferrite content of approximately 5 vol.\% (See Table 2). At a $\mathrm{Cr}_{\mathrm{eq}} / \mathrm{Ni}_{\text {eq }}$ ratio of approximately 1.58 this weld also falls in the FA solidification region on the WRC-1992 diagram, Figure 12. Images from the 98 weld are shown in Figure 5. Although not immediately obvious in the optical images (Figures 5(a) and (b)), TEM images showed an increased amount of $\delta$ ferrite compared to the EB weld. In some orientations skeletal ferrite was observed to partially "coat" the boundaries between the austenite grains (Figure 5(c)) while in other orientations small $\delta$ ferrite "grains" were observed (Figure5(d)). These ferrite morphologies are indicative of planar sections through a primary dendrite core and secondary branches of a dendrite, respectively. Similar to the EB weld microstructure, the skeletal ferrite in this weld metal is simply the retained ferrite at the cores of the primary ferrite dendrites that did not transform to austenite upon cooling [Ref 11]. TEM specimens from the region near the crack face showed an increase in dislocation density in both the ferrite and austenite (compare Figures 5(c) and (d) with Figure 5(e)). Deformation twins were also observed in the austenite, e.g., Figure 5(f).

Figures 5(g) and (h) are bright field and dark field images from the same region of a foil from this weld. (The dark field image was formed in the TEM by imaging with a diffracted electron beam from the austenite matrix). These two images show a thin region of $\delta$ ferrite that has been deformed by the interaction of deformation twins - originating in the austenite matrix. The "kink" in the $\delta$ ferrite provides some insight into deformation behavior of the weld metal and possibly the effectiveness of ferrite as a barrier to dislocation (and twin) movement. It appears that deformation twins in the austenite have deformed the thin, skeletal ferrite zone which resulted in twinning in the adjacent austenite grain. The ferrite 
(bcc iron) is expected to provide a barrier to deformation due to 1) the presence of the $\gamma / \delta$ interface (different orientation between crystals), 2) the transition in crystal structure from $\operatorname{fcc}(\gamma)$ to $\operatorname{bcc}(\delta)$, and 3$)$ the inherent, higher strength of the $\delta$ ferrite phase. All of these factors will influence the mechanical properties of the weld metal.

\section{Weld $-8 \% \delta$ ferrite}

The microstructure of the 48 weld, made using 308L filler wire on a 304L forging, was similar to that of the 98 weld. The light-optical images in Figures 6(a) and (b) show that the microstructure consisted of skeletal, $\delta$ ferrite. This result is consistent with the microstructure predicted using the WRC-1992 diagram (Figure 12). The measured vol.\% of retained ferrite in this weld was about $8 \%$, slightly higher than the 98 weld. The increase in $\delta$ ferrite content was discernable in the TEM images. Figures 6(c) and (d) are representative TEM images showing the ferrite morphology in this weld. Similar to the 98 weld, the ferrite was present as a discontinuous network separating the austenite grains. (Again, the ferrite in the weld metal is the untransformed portion at the cores of the primary ferrite dendrites.) In many regions of this weld the ferrite was "thicker" and more angular in shape (Figure 6(d)) compared to that in the EB and 98 welds.

\section{2/8309 Welds - $12 \% \delta$ ferrite}

The 8312 and 8309 welds were prepared on the 304L weld critical plate using two 308L wires twisted together with either one 312 MOD wire (weld 8312) or one 309L MOD wire (weld 8309). Table 2 shows that both welds had an average ferrite content of approximately $12 \%$ and a $\mathrm{Cr}_{\mathrm{eq}} / \mathrm{Ni}_{\mathrm{eq}}$ ratio of 1.82 . This $\mathrm{Cr}_{\mathrm{eq}} / \mathrm{Ni}_{\mathrm{eq}}$ ratio puts these welds just into the single phase ferrite solidification mode region of the WRC-1992 diagram (Figure 12). Comparison of the light-optical images in Figures 4-6 with those light-optical images in Figures 7 and 8 shows a definite transition from a skeletal ferrite microstructure to a more complex microstructure that resembles lathy ferrite (or lathy austenite). Typically, lathy ferrite welds can form as either primary lathy ferrite $\left(1.95<\mathrm{Cr}_{\mathrm{eq}} / \mathrm{Ni}_{\mathrm{eq}}<2.3\right)$ or primary lathy austenite depending on the $\mathrm{Cr}_{\mathrm{eq}} / \mathrm{Ni}_{\text {eq }}$ ratio with higher $\mathrm{Cr}_{\mathrm{eq}} / \mathrm{Ni}_{\mathrm{eq}}$ ratios favoring lathy austenite $\left(\mathrm{Cr}_{\mathrm{eq}} / \mathrm{Ni}_{\mathrm{eq}}>2.3\right)$ [Ref. 9]. Even though the lathy ferrite/austenite morphologies observed in these images are typically reported in welds from FA region (primary ferrite/secondary solidification of austenite) they can form in welds that solidify as single phase ferrite [Ref 11] where Widmanstätten austenite would be the predominant microstructure at room temperature.

Typical ferrite/austenite morphologies observed in these welds are shown in the TEM images in Figure 7(b) and (c) and 8(b) and (c). The TEM revealed a microstructure that was mostly austenitic with regions of cellular-like ferrite (Figure 7(c)) and other areas that contained lathy ferrite/austenite (Figures 7(d) and 8(c) and (d)). In addition to the different ferrite/austenite morphologies observed in these two welds, the ferrite appeared to be much more continuous compared to the lower $\mathrm{Cr}_{\mathrm{eq}} / \mathrm{Ni}_{\mathrm{eq}}$ ratio welds. This observation could be important in helping to determine the effect(s) of microstructure on the fracture toughness properties of these weldments. 
These welds, made by using 312 MOD filler on a conventionally forged 21-6-9 forging and a HERF 304L forging, respectively, contained approximately 24 vol. \% ferrite and had nearly identical microstructures (see Figures 9 and 10). The light-optical images (Figures 9(a) and (b) and 10(a) and (b)) show a complex microstructure similar to that seen in Figure 7(a) and (b) and Figure 8(a) and (b) above. Again, the microstructure was mostly austenitic with regions of cellular-ferrite (Figure 9(c)) and lathy austenite/ferrite (e.g. Figures 9(d), 10 (c) and $10(d))$.

Another obvious difference in the weld microstructures was the presence of numerous oxide inclusions in these two welds. Oxide particles measuring in the 0.5-10 $\mu \mathrm{m}$ range and were distributed throughout the weld metal. EDS analysis showed that they were enriched in Mn, $\mathrm{Cr}, \mathrm{Ti}, \mathrm{Al}$, (and O) when compared to the base weld metal. Additionally, all particles were "located" in the austenite matrix or at the austenite/ferrite interphase boundaries. The formation of particles in these welds is believed to be a direct result of oxide impurities present in the 309L MOD and 312 MOD powder metal cored weld wires. The presence of particles in the weld metal could affect the mechanical properties of the weld where they might serve as nucleation sites for microvoids.

More insight into the deformation behavior of these welds can be seen in Figures 9(f) and 10(f). Figure 9(f) shows a large number of deformation twins in the austenite "grains" of the weld metal. The higher magnification image in Figure 10(f) provides a better look at this phenomenon. The $\delta$ ferrite in these welds seems to provide a sufficient barrier to plastic deformation (compared to Figures 5(e) and (f)). Extensive deformation appears to be limited mainly to the austenite grains located within the $\delta$ ferrite cells.

\section{$\underline{49 \text { Weld }-33 \% \delta \text { ferrite }}$}

The weld with the most ferrite investigated in this study was the 49 weld made using 309L MOD wire on a HERF 304L forging. The measured ferrite content of this weld was about 33 vol.\% and the $\mathrm{Cr}_{\text {eq }} / \mathrm{Ni}_{\text {eq }}$ ratio was 2.34 (see Table 2). Figures 11(a) and (b) are light-optical images from this weld showing a microstructure that looks much different in appearance to the other welds in this study welds. The low magnification TEM image in Figure 11(c) shows a microstructure that is predominately Widmanstätten or acicular in appearance. TEM images also show that the $\delta$ ferrite is the majority phase (matrix phase) in this weld and that it forms a continuous network in the regions examined. The continuous nature of the $\delta$ ferrite is evident in Figures 11(d) through (f). Figure 11(d) clearly shows small, austenite "grains" surrounded by the $\delta$ ferrite matrix. The continuous nature of the ferrite is also evident in Figure 11(e) and (f), bright field and dark field images, respectively, from the same area. These images are typical of a weld that solidified as mostly single phase ferrite as predicted by the WRC-1992 diagram in Figure 12.

The Widmanstätten microstructure that forms in high $\mathrm{Cr}_{\mathrm{eq}} / \mathrm{Ni}_{\mathrm{eq}}$ welds is thought to occur by nucleation and growth of austenite from a single phase ferrite structure [Ref. 8,9,11]. The austenite nucleates preferentially at the ferrite grain boundaries and grows into the ferrite grains resulting in a distinct crystallographic orientation relationship between the two phases, 
this relationship is known as either the Kurdjumov-Sachs (K-S) or the NishiyamaWasserman (N-W) relationship and can be proven by electron diffraction [Ref. 12]; however, verification of the orientation relationship was beyond the scope of this study. Clearly evident in the images from this weld are the distinct, planar phase boundaries between the austenite and ferrite. The planar nature of the austenite/ferrite boundaries can be seen in Figures 11(g) and (h). In Figure 11(g) the austenite and ferrite are arranged in alternating layers. In Figure 11(h) several needle-shaped austenite grains appear to have grown into the ferrite matrix. The small austenite grain in the center of the image in Figure 11(h) is believed to be an acicular austenite grain that has been sectioned normal to its growth direction. This grain is very similar in appearance to the small, facetted grains in Figures 11(d) through (g).

Although not readily apparent from the TEM images of this weld, many oxide particles were also observed in this weld, a consequence of using the 309L MOD filler wire. Most of the particles were located at the austenite/ferrite boundaries. This may be coincidental or it may mean that the oxide particles acted as nucleation sites for austenite formation.

\section{SUMMARY}

The microstructures of the welds examined in this study were very complex. At the lowest ferrite levels (welds - EB, 98, and 48) the welds were mainly austenite (matrix phase) and skeletal ferrite. The ferrite was discontinuous in these welds and was observed to partially "coat" the austenite grain boundaries. In TEM specimens sectioned close to the fracture surface of the test specimens, increased numbers of dislocations were observed in both the austenite and ferrite with deformation twins forming in the austenite.

At higher ferrite levels the weld microstructures became more complex. In welds 8312 and 8309 (12 vol.\% ferrite) and welds 912 and 412 (24 vol.\% ferrite) the austenite was the matrix phase and the ferrite formed a nearly continuous network throughout the areas examined. The ferrite and austenite were lathy in appearance in some areas whereas in other areas the ferrite was cellular in appearance, completely surrounding small "grains" of austenite. Deformation twinning was observed in the austenite regions in welds 912 and 412 in specimens from near the fracture surface. The 912 and 412 welds also contained a large number of oxide particles located in the austenite matrix and at the austenite/ferrite phases boundaries. These particles most likely originated from weld wire impurities.

The highest ferrite microstructure examined in this study was created by welding the 304L forging with 309L MOD filler wire. The measured ferrite level in this weld was about 33 vol.\%. The microstructure that developed was mostly Widmanstätten in appearance. Unlike the other welds examined in this study, the ferrite phase in the areas examined by TEM was the matrix phase instead of the austenite. The Widmanstätten microstructure is predicted in the literature for welds that solidify as single phase ferrite and subsequently transform to austenite at low temperatures. Many austenite morphologies were observed. The somewhat facetted austenite and the planar boundary segments suggest a crystallographic relationship between the two phases as would be consistent for a nucleation and growth mechanism for austenite formation. Similar to the 912 and 412 welds, many oxide particles were observed in this weldment. 


\section{FUTURE PLANS}

The work described in this paper provides the background for the major thrust of the TEM work - characterization of the helium bubble microstructures that develop in austenite/ferrite weldments. Future work will investigate the helium bubble microstructures in tritiumcharged-and-aged samples from the same sample matrix as the current study. Special emphasis will be place on determining the effectiveness of the austenite/ferrite interface as a helium bubble nucleation site since these interfaces are believe to play an important role in the fracture behavior of the fusion welds. Additionally, the helium bubble distribution, if any, in the $\delta$ ferrite will be characterized and compared to the often-studied bubble microstructure in austenite.

\section{ACKNOWLEDGEMENTS}

The authors would like to express their appreciation to S. L. West for his valuable technical input, to G. K. Chapman for preparing the weld test specimens, and to D. Z. Nelson and C. N. Forman for preparing and photographing the weld microstructures. The authors also wish to thank McKay Welding Products for the custom fabrication of the 312 MOD and 309L MOD wires used in this study.

\section{REFERENCES}

1. M. J. Morgan and David Lohmeier, "Threshold Stress Intensities and Crack Growth in Tritium-Exposed HERF Stainless Steels", Proceedings of the Fourth International Conference on the Effects of Hydrogen on the Behavior of Materials, N. R. Moody and A. W. Thompson, eds., TMS, Warrendale, PA, 1990, pp. 459-68.

2. M. J. Morgan and M. H. Tosten, "Tritium and Decay Helium Effects on the Fracture Toughness Properties of Types 316L, 304L, and 21Cr-6Ni-9Mn Stainless Steels", Proceedings of the Fifth International Conference on the Effects of Hydrogen on the Behavior of Materials, A. W. Thompson and N. R. Moody, eds., TMS, Warrendale, PA, 1996, pp. 873-82.

3. A. L. Schaeffler, "Constitution Diagram for Stainless Steel Weld Metal", Metals Progress, Vol. 56, No. 11, 1949, pp. 680-680B.

4. C. J. Long and W. T. DeLong, "The Ferrite Content of Austenitic Stainless Steel Weld Metal", Welding J., Vol. 52, No. 7, 1973, pp. 281s-97s.

5. T. A. Siewert, C. N. McCowan, and D. L. Olson, "Ferrite Number Prediction to 100 FN in Stainless Steel Weld Metal", Welding J.,. Vol. 67, No. 12, 1988, pp. 289s-98s.

6. D. J. Kotecki and T. A. Siewert, "WRC-1992 Constitution Diagram for Stainless Steel Weld metals: A Modification of the WRC-1988 Diagram", Welding J., Vol. 71, No. 5, 1992, pp. 171s-78s. 
7. $\quad$ "Standard Practices for Calibrating Magnetic Instruments to Measure the Delta Ferrite Content of Austenitic and Duplex Ferritic-Austenite Stainless Weld Metal, ANSI/AWS A4.2M/4.2, AWS, 1997.

8. N. Suutala, T. Takalo, and T. Moisio, "The Relationship Between Solidification and Microstructure in Austenitic-Ferritic Stainless Steel Welds", Met. Trans. A, Vol. 10A, No. 4, 1979, pp. 512-14.

9. N. Suutala, T. Takalo, and T. Moisio, "Single Phase Ferritic Solidification Mode in Austenitic-Ferritic Stainless Steel Welds", Met. Trans. A, Vol. 10A, No. 8, 1979, pp. 1183-90.

10. S. A. David, "Ferrite Morphology and Variations in Ferrite Content in Austenitic Stainless Steel Welds", Welding J., Vol. 60, No. 4, 1981, pp. 63s-71s.

11. J. A. Brooks and A. W. Thompson, "Microstructural Development and Solidification Cracking Susceptibility of Austenitic Stainless Steel Welds", Int. Mater. Rev., Vol 36, No. 1, 1991, pp. 16-44.

12. K.W. Andrews, D.J. Dyson, and S.R. Keown: Interpretation of Electron Diffraction Patterns, $2^{\text {nd }}$ ed., pp. 158-175, Adams and Hilger Ltd., London, 1971. 


\begin{tabular}{|c|c|c|c|c|c|c|}
\hline \multicolumn{7}{|c|}{$\begin{array}{c}\text { Table } 1 \\
\text { Compositions and } \mathrm{Cr}_{\mathrm{eq}} / \mathrm{Ni}_{\mathrm{eq}} \text { Ratios of Materials Used }\end{array}$} \\
\hline & $\begin{array}{c}\text { 304L } \\
\text { HERF }\end{array}$ & $\begin{array}{c}21-6-9 \\
\text { CF }\end{array}$ & $\begin{array}{c}\text { 304L } \\
\text { WC Plate }^{\mathrm{a}}\end{array}$ & $\begin{array}{l}\text { 308L } \\
\text { Wire }\end{array}$ & $\begin{array}{l}\text { 309L MOD } \\
\text { Wire }^{b}\end{array}$ & $\begin{array}{l}312 \text { MOD } \\
\text { Wire }^{c}\end{array}$ \\
\hline $\mathrm{Cr}$ & 19.9 & 19.3 & 18.9 & 20.5 & 23.56 & 28.7 \\
\hline $\mathrm{Ni}$ & 10.4 & 6.7 & 10.5 & 10.3 & 8.55 & 9.17 \\
\hline $\mathrm{Mn}$ & 1.7 & 9.9 & 1.77 & 1.56 & 1.2 & 1.45 \\
\hline Mo & 0.04 & - & - & $<0.01$ & 2.5 & 0.27 \\
\hline $\mathrm{C}$ & 0.029 & 0.031 & 0.019 & 0.028 & 0.02 & 0.05 \\
\hline $\mathrm{Si}$ & 0.63 & 0.38 & 0.30 & 0.5 & 0.64 & 0.51 \\
\hline $\mathrm{Cu}$ & - & - & 0.125 & 0.015 & 0.31 & 0.31 \\
\hline $\mathrm{P}$ & 0.015 & 0.01 & - & 0.006 & 0.022 & 0.023 \\
\hline $\mathrm{S}$ & 0.002 & 0.001 & - & 0.012 & 0.008 & 0.008 \\
\hline $\mathrm{N}$ & 0.039 & 0.28 & 0.045 & 0.055 & - & - \\
\hline Co & 0.03 & - & - & 0.068 & - & - \\
\hline $\mathrm{Cr}_{\mathrm{eq}}$ & 19.94 & 19.30 & 18.90 & 20.50 & 26.06 & 28.97 \\
\hline $\mathrm{Ni}_{\mathrm{eq}}$ & 12.20 & 13.39 & 12.07 & 12.38 & 9.33 & 11.00 \\
\hline $\mathrm{Cr}_{\mathrm{eq}} / \mathrm{Ni}_{\mathrm{eq}}$ & 1.64 & 1.44 & 1.56 & 1.66 & 2.79 & 2.63 \\
\hline
\end{tabular}

a304L Plate, in-house EDS and ICPES results

${ }^{\mathbf{b}}$ Manufactured as 309L and 312 metal sheath with powder metal core

$\mathrm{Cr}_{\text {eq }}=\mathrm{Cr}+\mathrm{Mo}+0.7 \mathrm{Nb}$

$\mathrm{Ni}_{\text {eq }}=\mathrm{Ni}+35 \mathrm{C}+20 \mathrm{~N}+0.25 \mathrm{Cu}$ 


\begin{tabular}{|c|c|c|c|c|}
\hline \multicolumn{5}{|c|}{$\begin{array}{c}\text { Table } 2 \\
\text { Fusion Welds }\end{array}$} \\
\hline$\underline{\text { Sample ID }}$ & $\underline{\text { Base Metal }}^{\mathrm{a}}$ & Filler & $\begin{array}{l}\text { Vol.\% } \\
\text { Ferrite }^{b}\end{array}$ & $\underline{\mathrm{Cr}_{\mathrm{eq}}} / \mathbf{N i}_{\underline{e}}{ }^{\mathrm{c}}$ \\
\hline EB & 304L (WC Plate) & EB Weld & 4 & 1.56 \\
\hline 98 & 21-6-9 (CF) & $308 \mathrm{~L}$ & 5 & 1.58 \\
\hline 48 & 304L (HERF) & $308 \mathrm{~L}$ & 8 & 1.65 \\
\hline 8309 & 304L (WC Plate) & 308L/309LM Mix & \multirow{2}{*}{12} & 1.82 \\
\hline 8312 & 304L (WC Plate) & 308L/312M Mix & & 1.82 \\
\hline 912 & 21-6-9 (CF) & $312 \mathrm{M}$ & 24 & 2.17 \\
\hline 412 & 304L (HERF) & $312 \mathrm{M}$ & 24 & 2.27 \\
\hline 49 & 304L (HERF) & 309LM & 33 & 2.34 \\
\hline
\end{tabular}

${ }^{\mathrm{a}} \mathrm{WC}$ - weld critical, HERF - high energy rate forged, CF - conventionally forged

${ }^{\mathbf{b}}$ Average ferrite content measured at center of notch

'Based on Table 1 compositions, 35\% dilution of the weld by the base metal, and the WRC$1992 \mathrm{Cr}$ and Ni equivalency equations. 


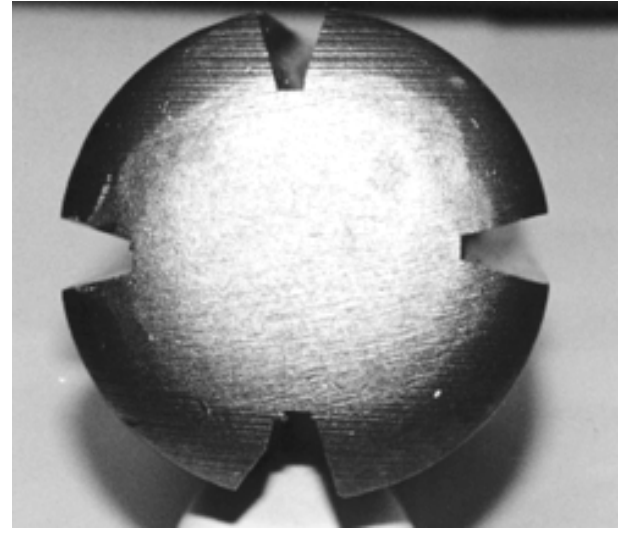

a.

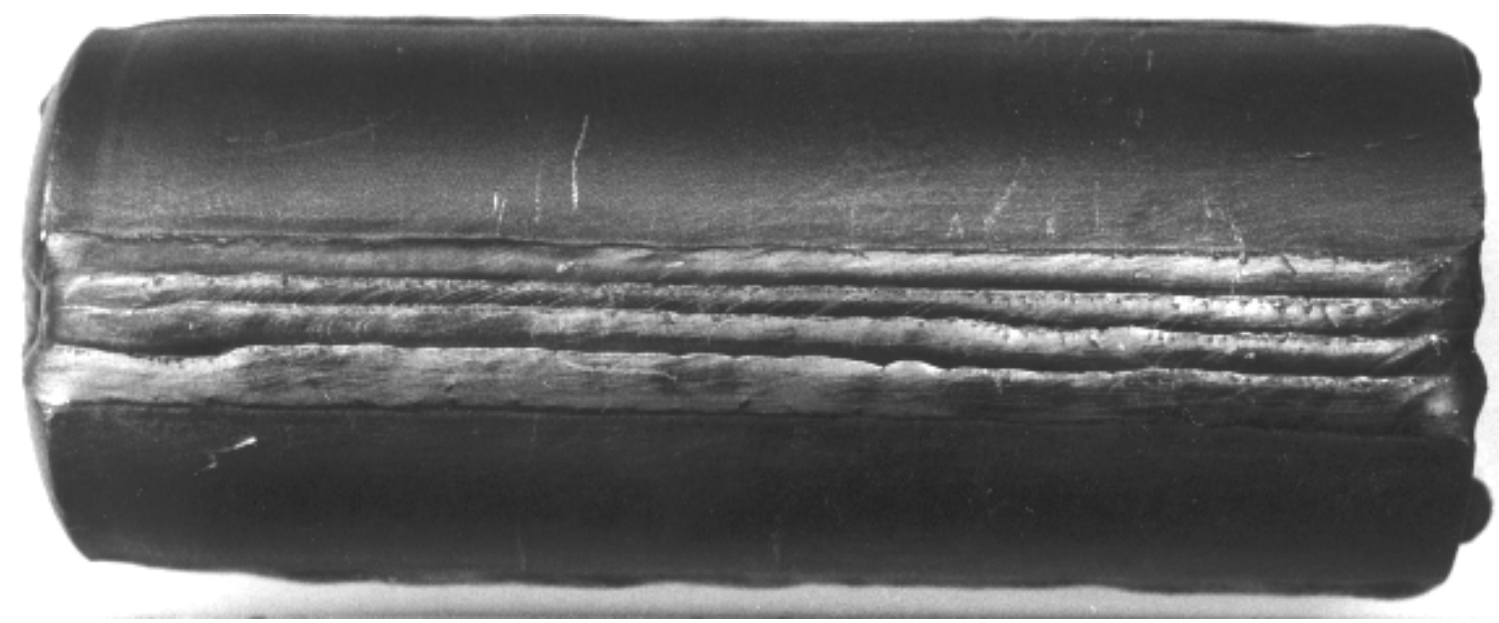

C.

Figure 1. Images of a 3.125" diameter 304L HERF forging showing the (a) V-grooves prior to machine welding, (b) cross-section of forging after welding, and (c) one weld (showing multiple passes) along the 8 " length of the same forging. 


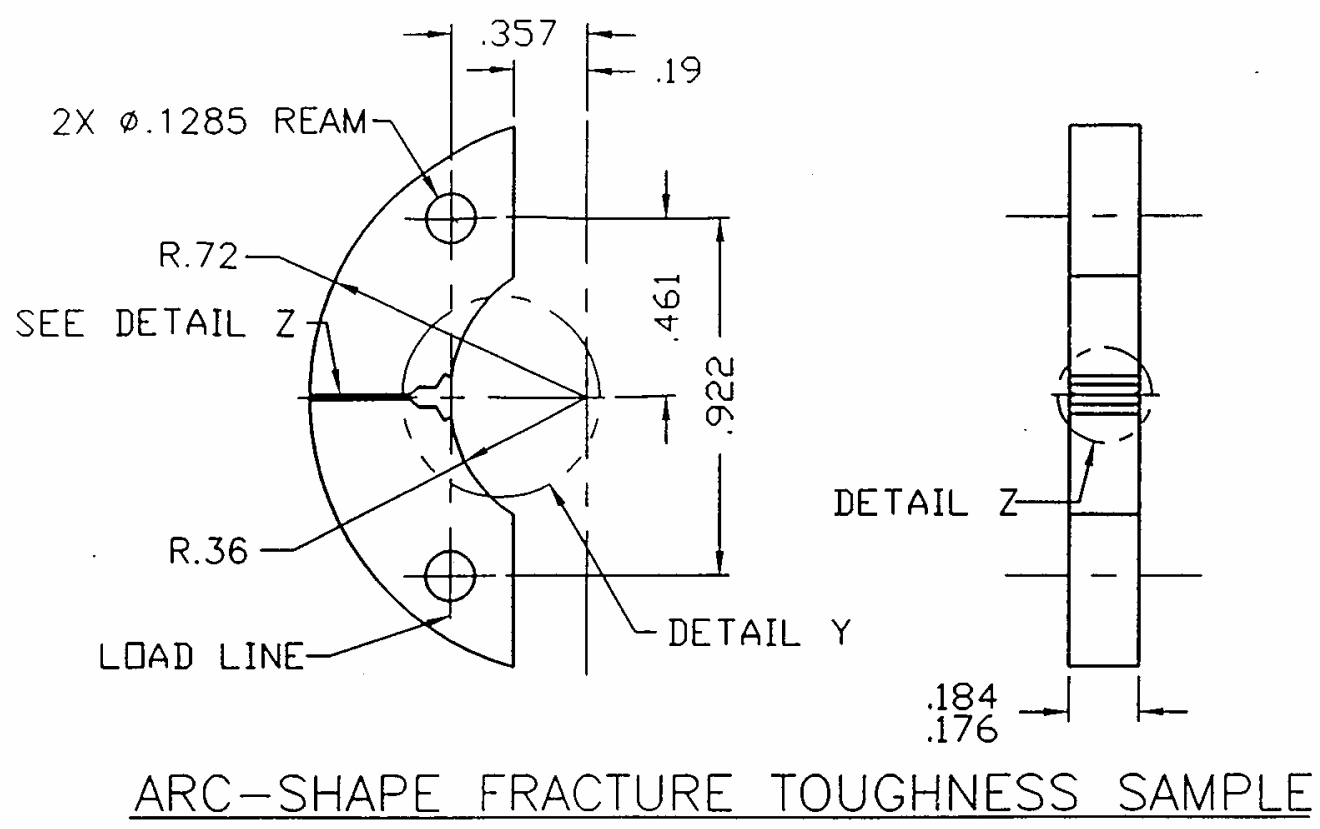

Figure 2. The type of fracture toughness specimen machined from the forgings and weld critical plate. Specimens were machined so that the notch would be located at the weld center line. 


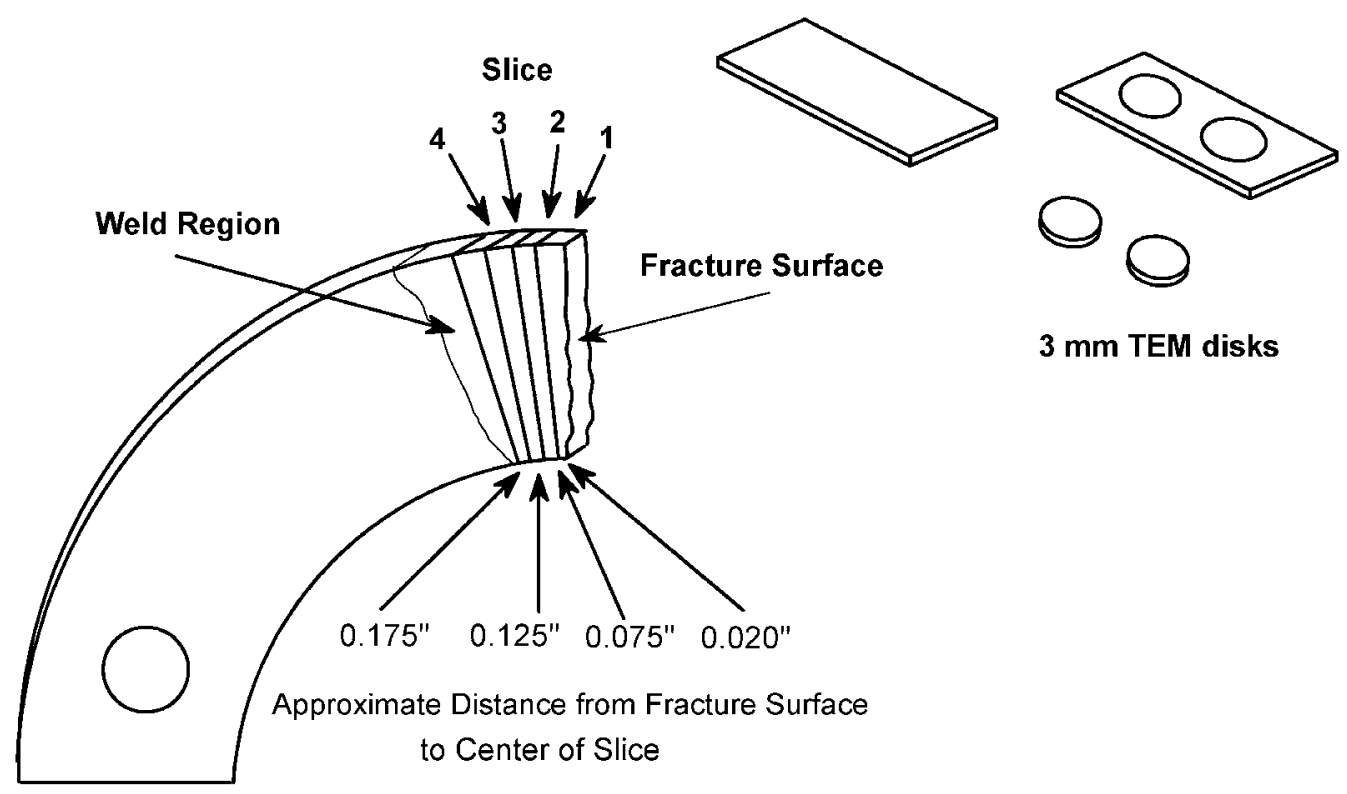

Figure 3. Schematic diagram illustrating the sectioning procedure used to generate TEM disks from the fusion weld region. TEM samples were prepared from as close to the fracture surface as possible - potentially a plastically deformed region. Additional slices were sectioned from the weld and heat-affected zone. 


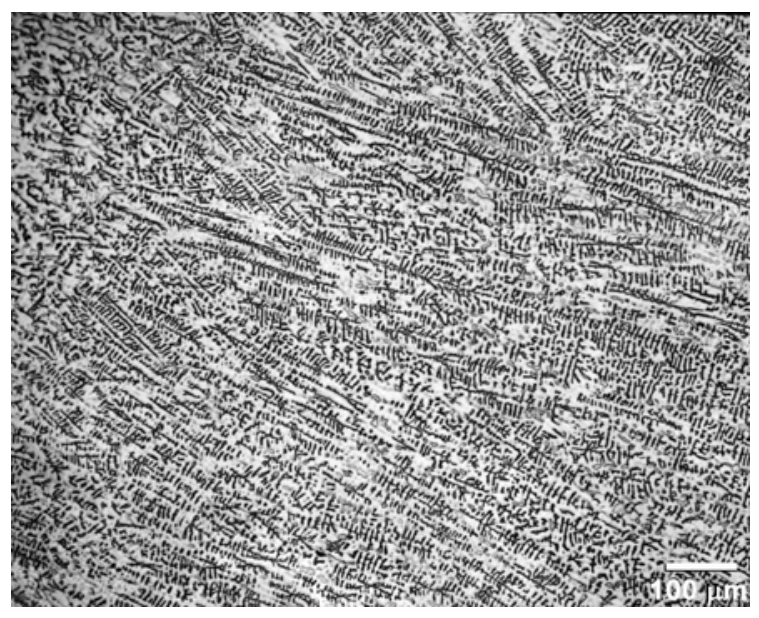

a

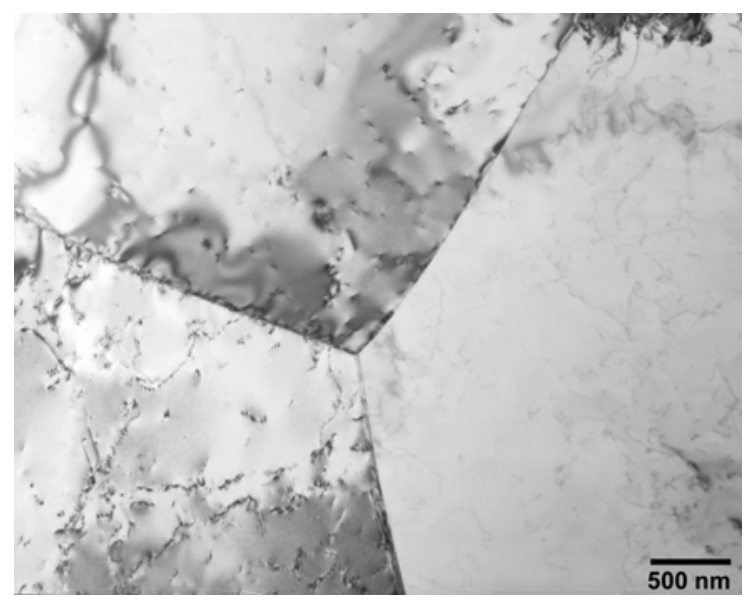

C

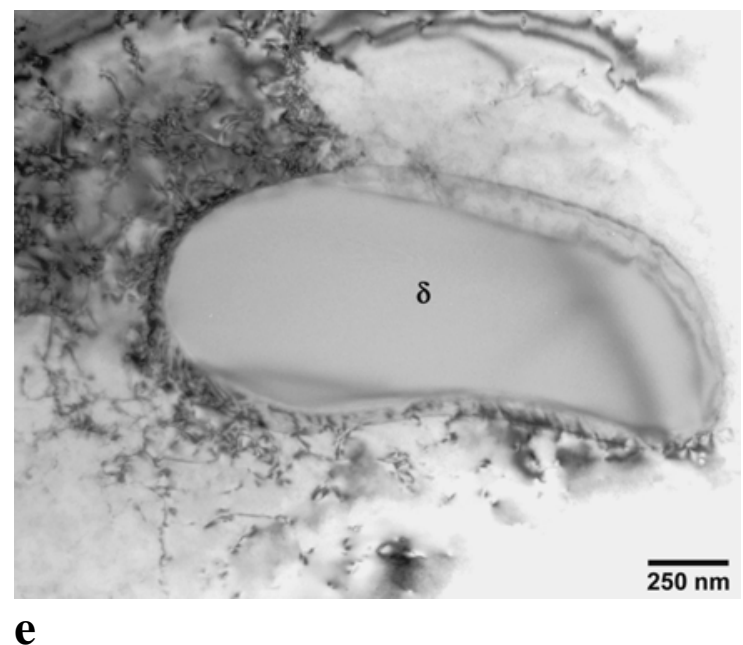

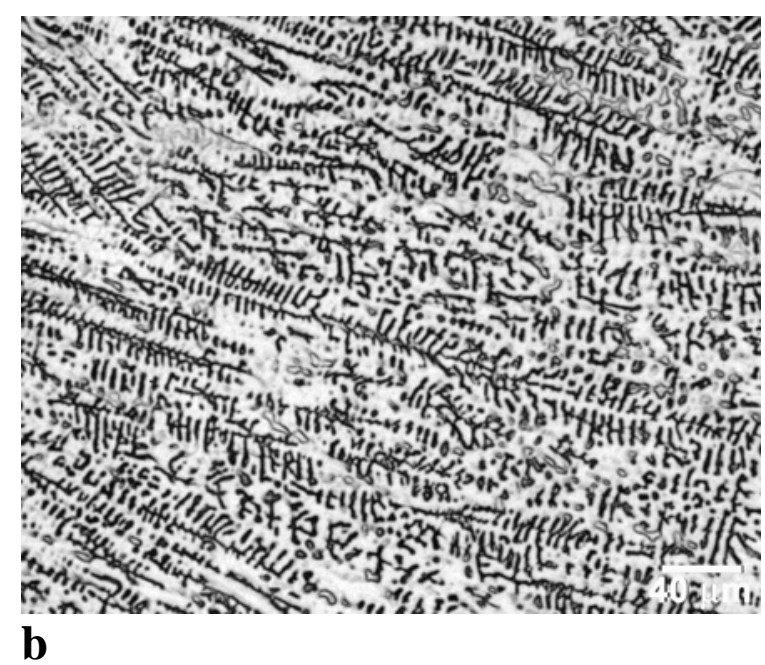
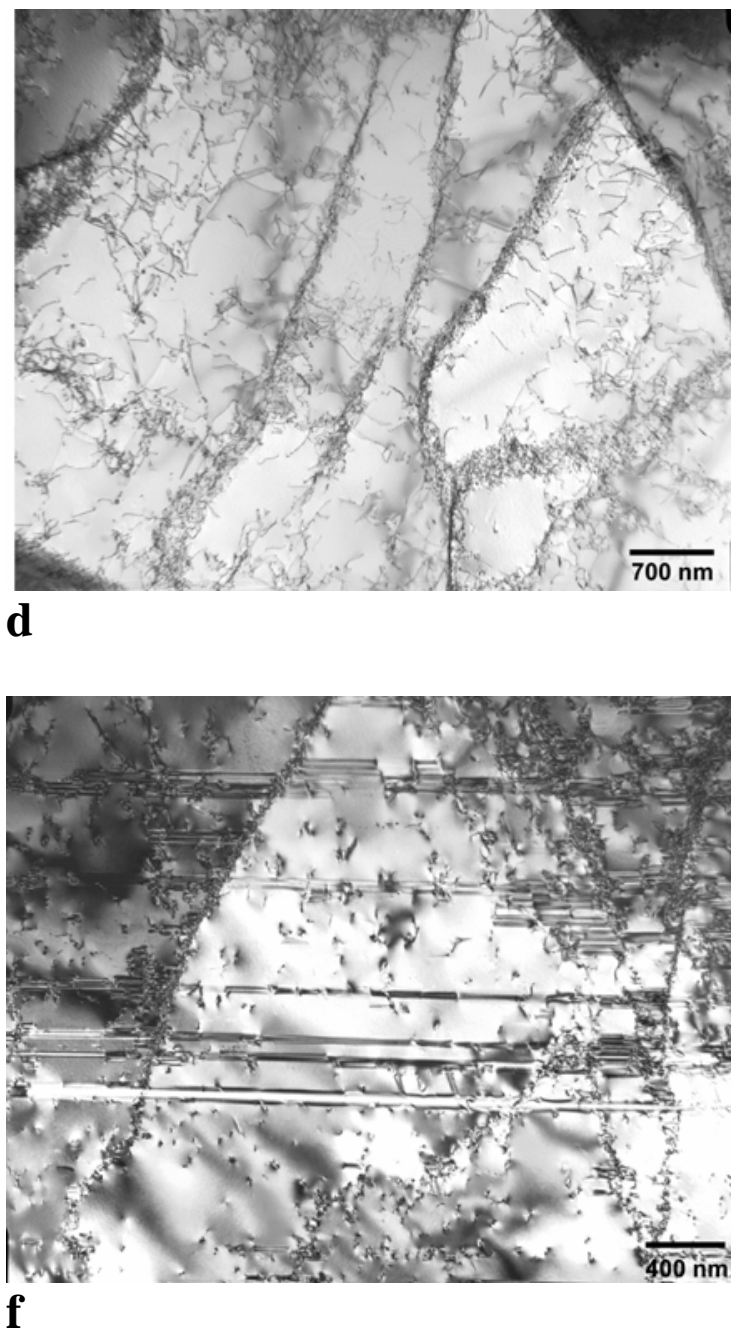

Figure 4. Skeletal ferrite in EB weld on 304L weld-critical plate. (a) and (b) Light-optical images, (c) Triple junction in austenite - equiaxed grains, (d) Subgrains and dislocations in $\gamma$, (e) Small $\delta$ ferrite "grain", and (f) Deformation twinning and faulting along with an increased dislocation density near the fracture surface. 


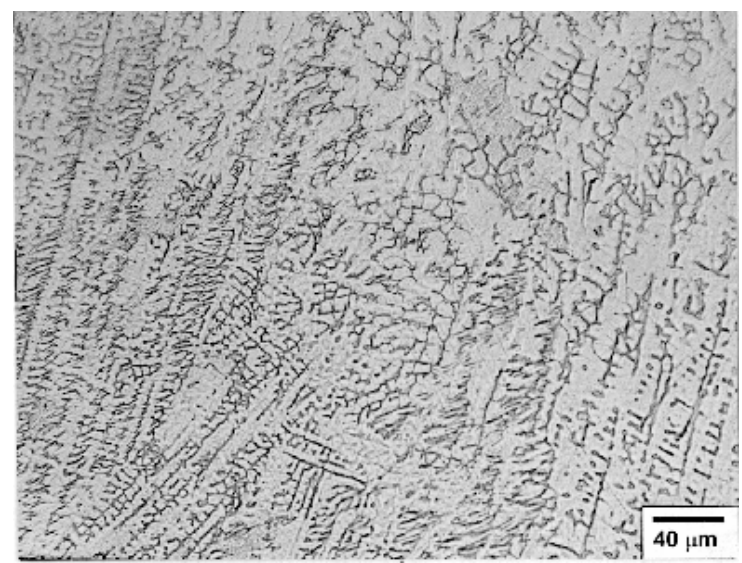

a

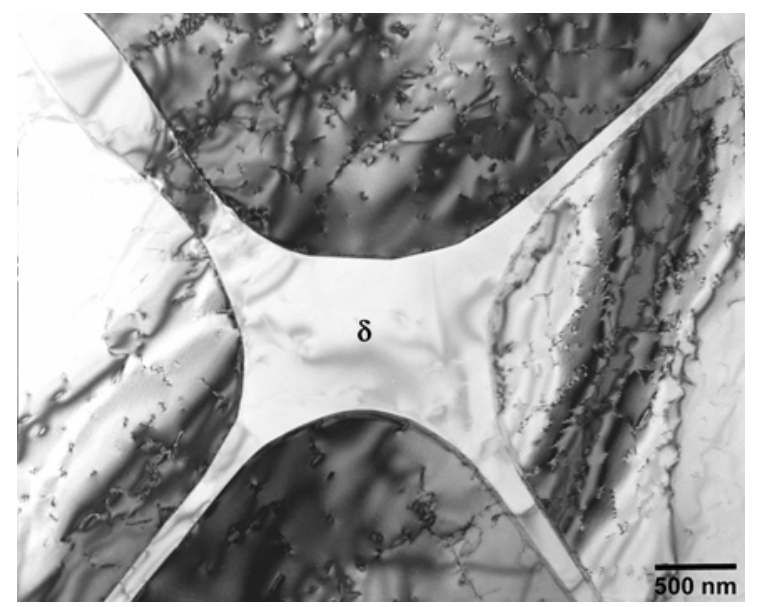

C

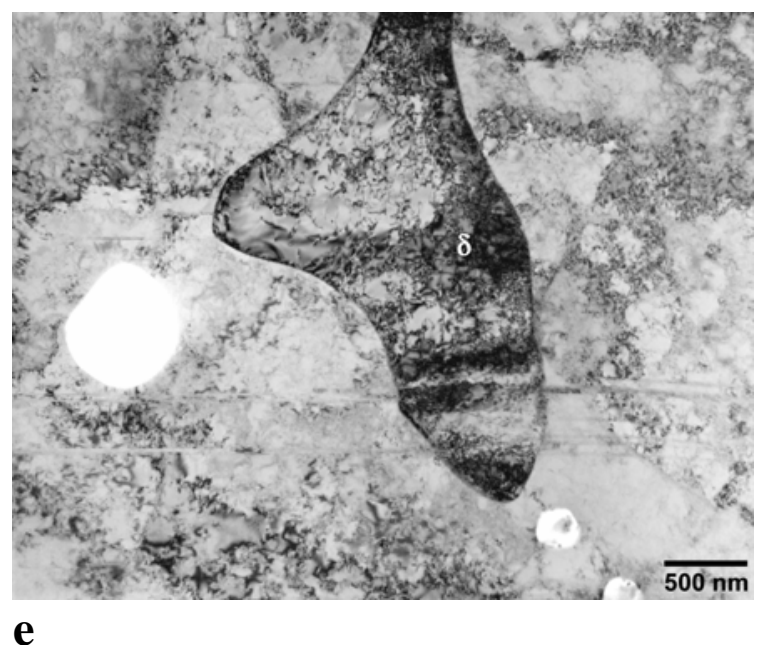

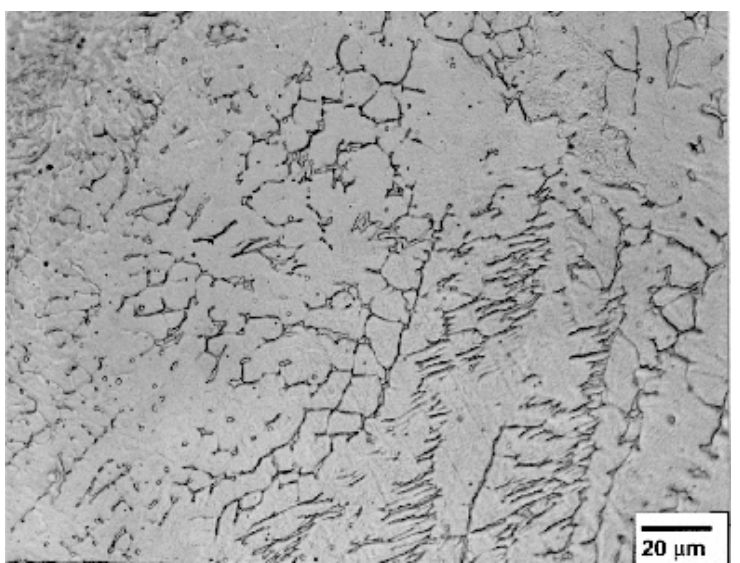

b

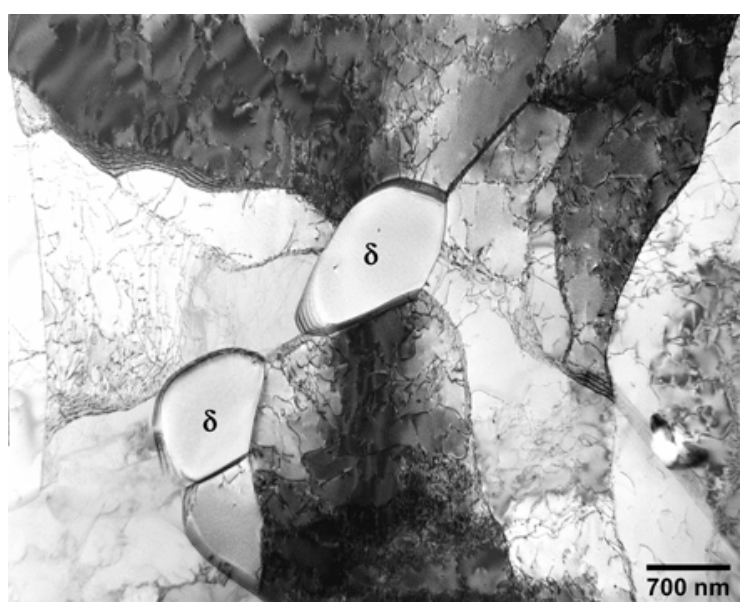

d

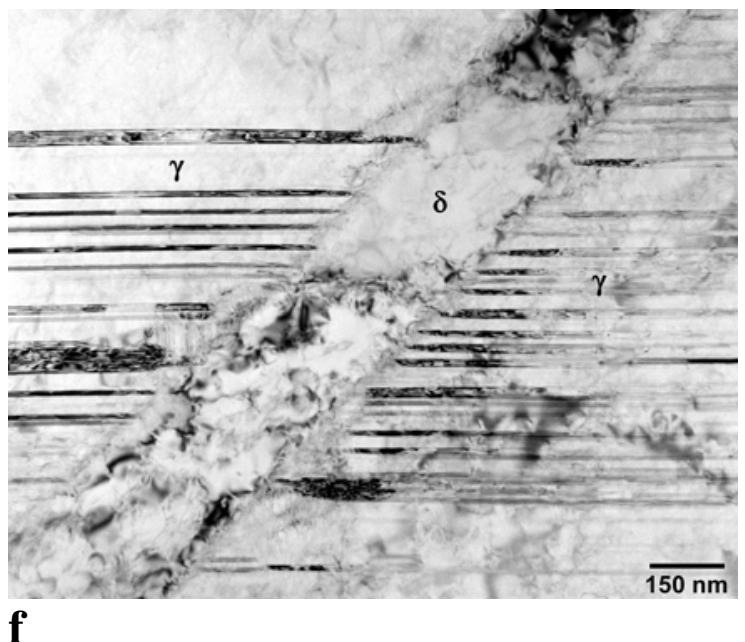

Figure 5. Microstructure of the 98 weld - 308L filler wire/21-6-9 conventional forging. (a) and (b) Light-optical images, (c) - (h) TEM images showing skeletal, $\delta$ ferrite and austenite, (e) Increased deformation results in more dislocation in both phases, and (f) - (h) Presence of deformation twins in the austenite. 
Figure 5 continued

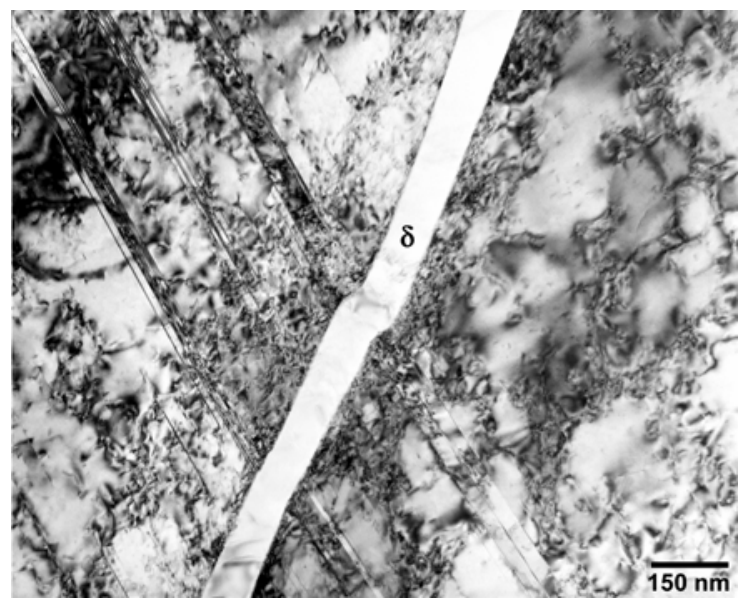

g

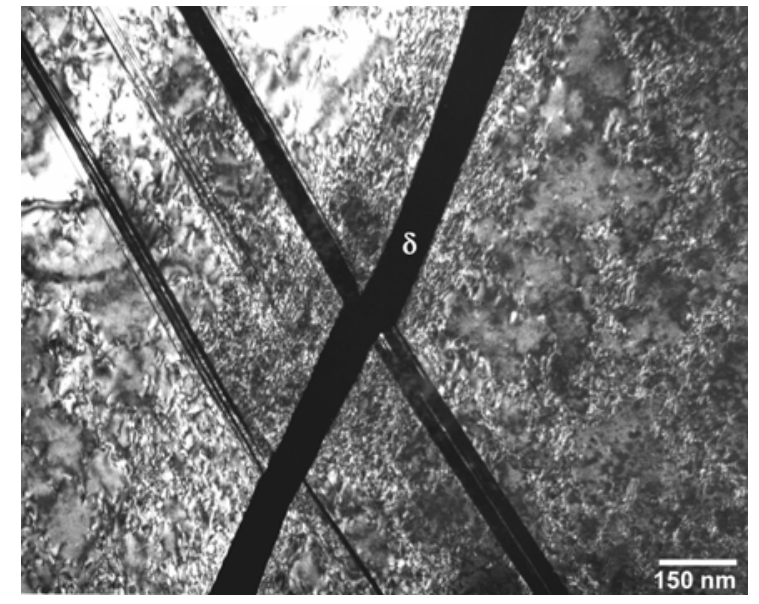

h 


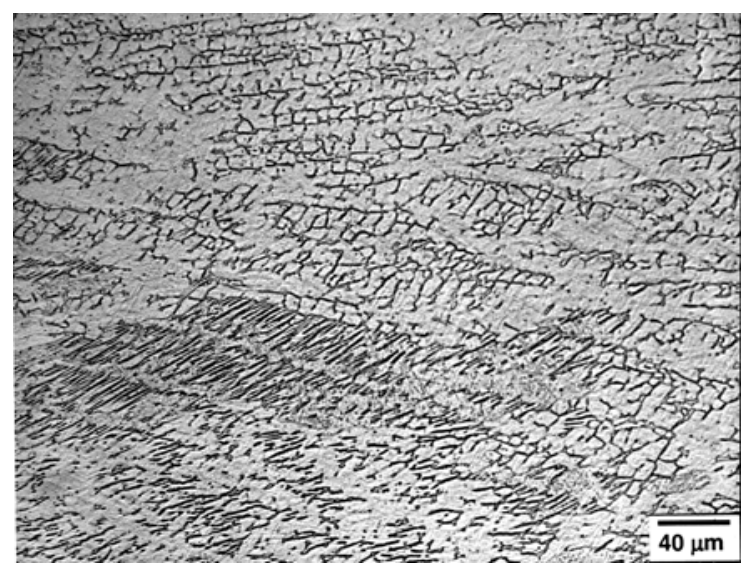

a

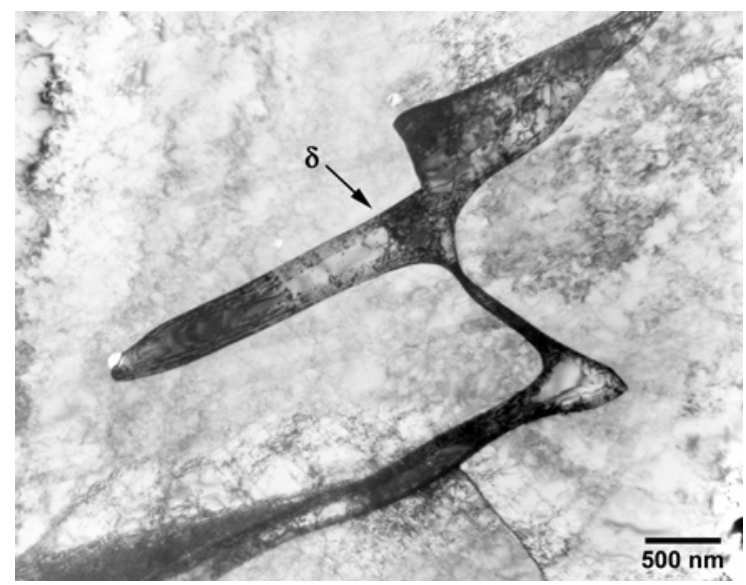

C

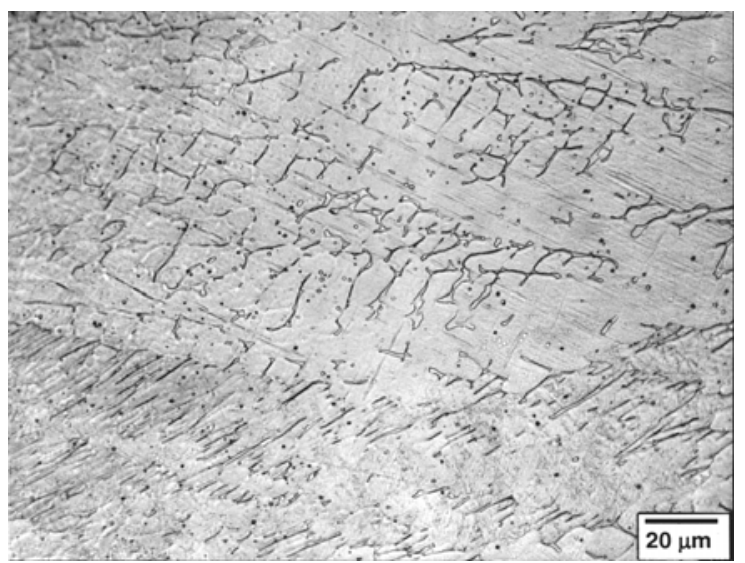

b

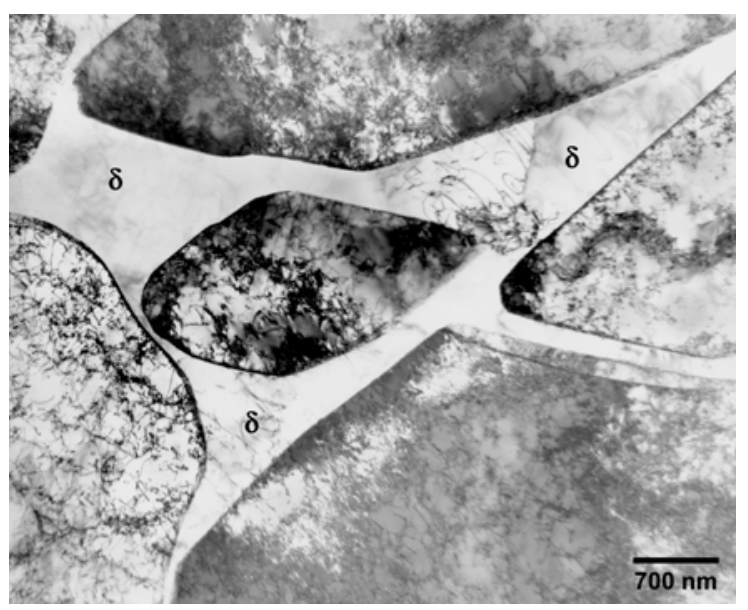

d

Figure 6. Microstructure of the 48 weld - 308L filler wire/304L HERF forging. (a) and (b) Light-optical images, and (c) and (d) TEM images of austenite and skeletal $\delta$ ferrite. 


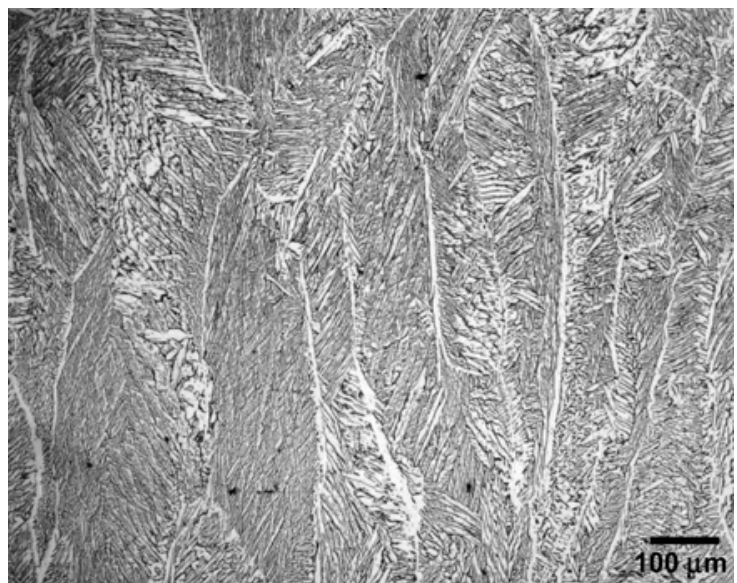

a

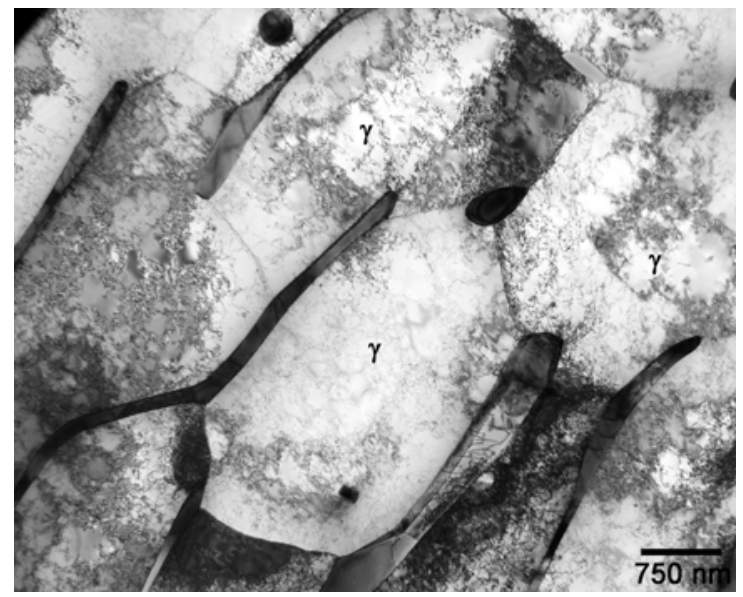

C

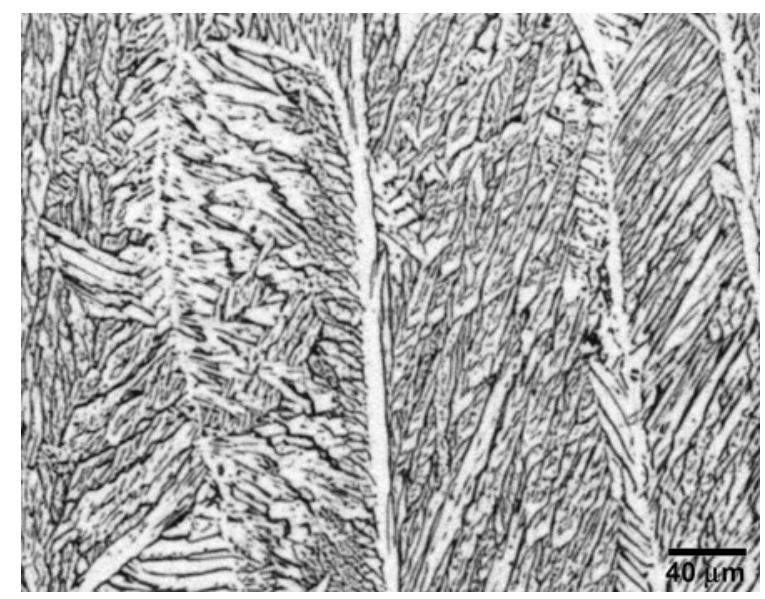

b

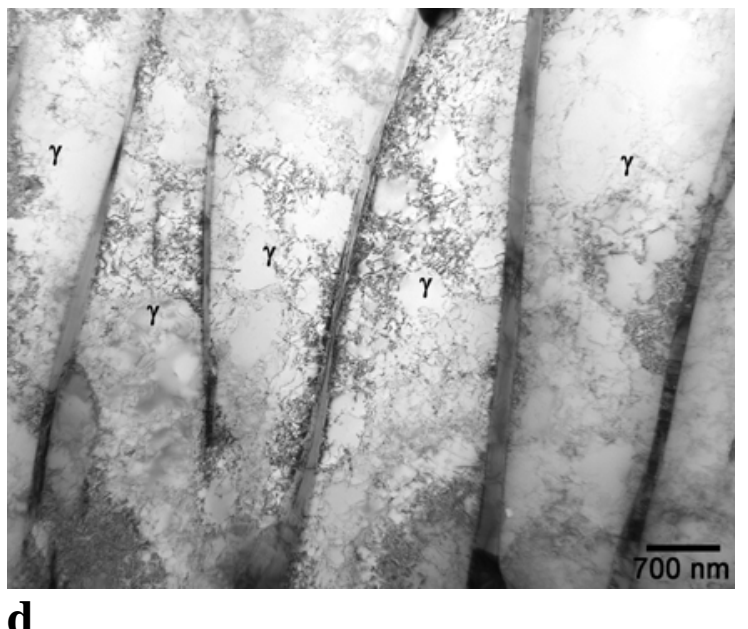

Figure 7. Microstructure of 8312 weld-308L and 312 MOD wires/weld critical plate. (a) and (b) Light-optical micrographs, (c) and (d) TEM images of the ferrite morphologies observed in this specimen material. 


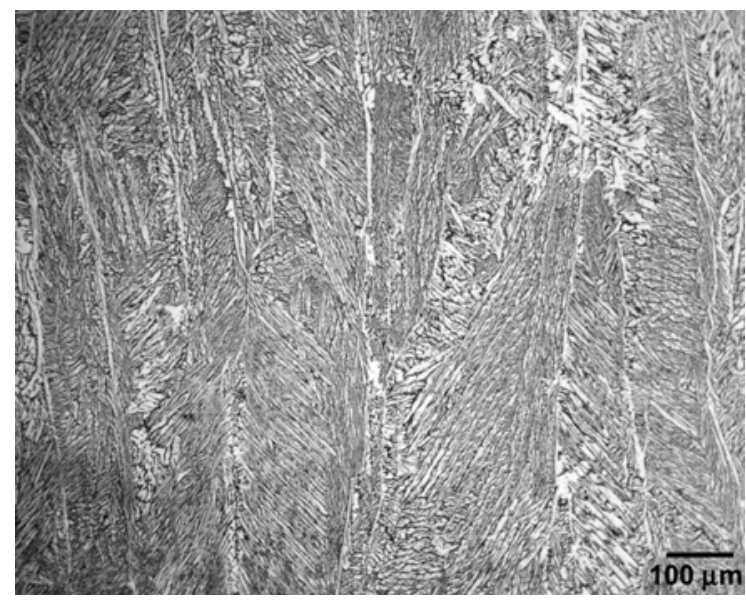

a

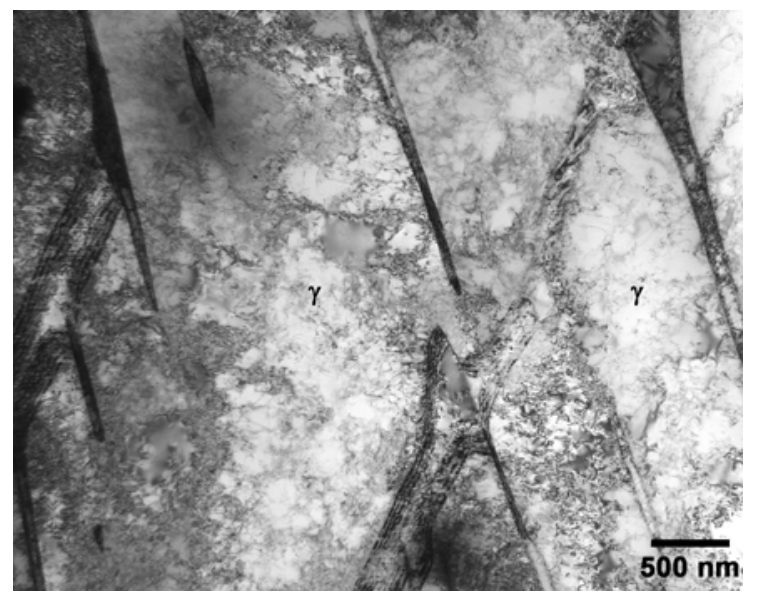

C

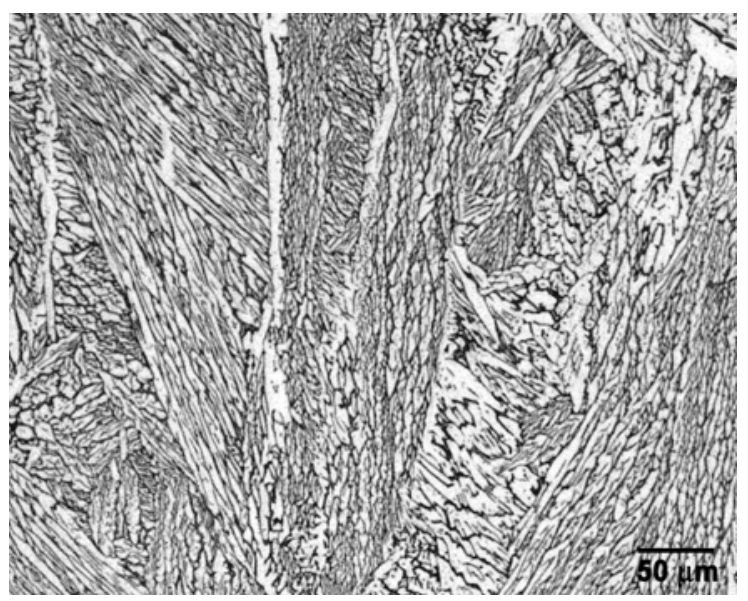

b

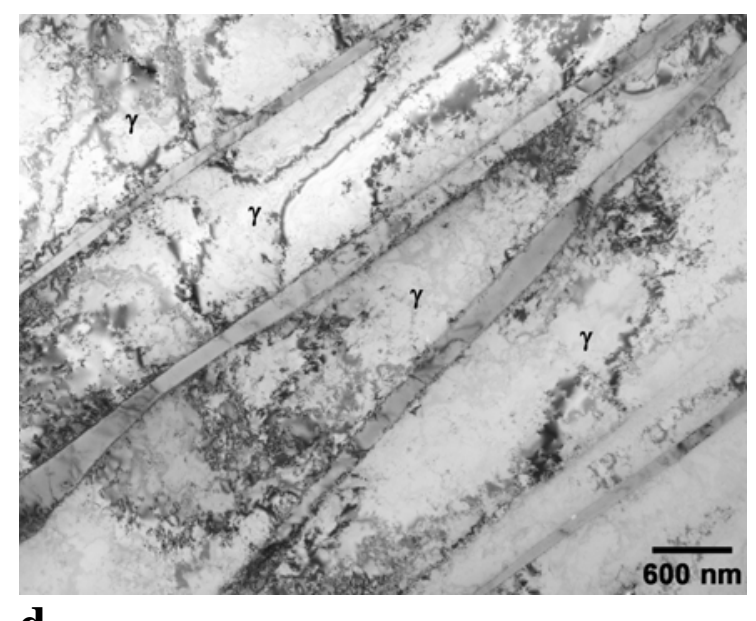

Figure 8. Microstructure of 8309 weld - 308L and 309L MOD wires/weld critical plate. (a) and (b) Light-optical micrographs, (c) and (d) TEM images of the lathy ferrite/austenite. 


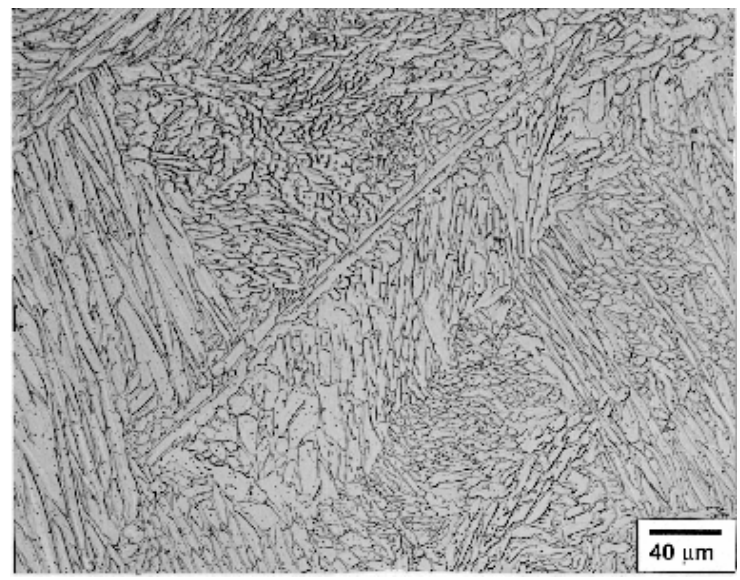

a

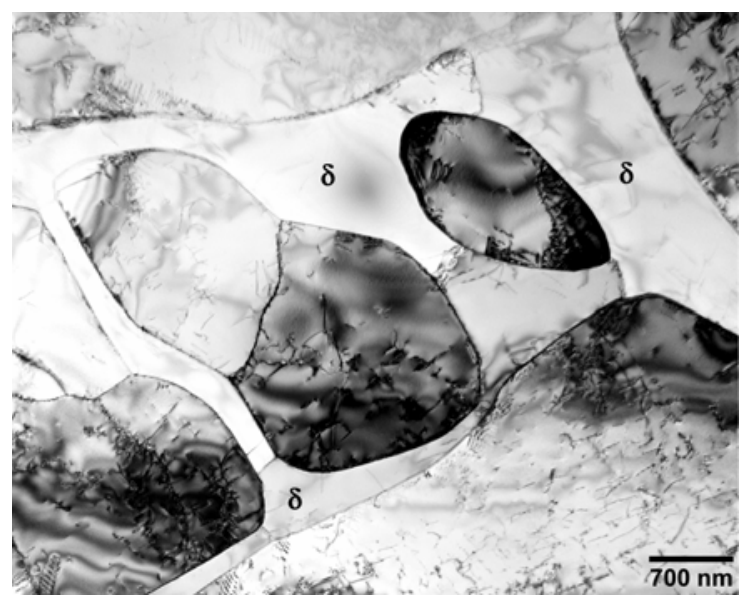

C

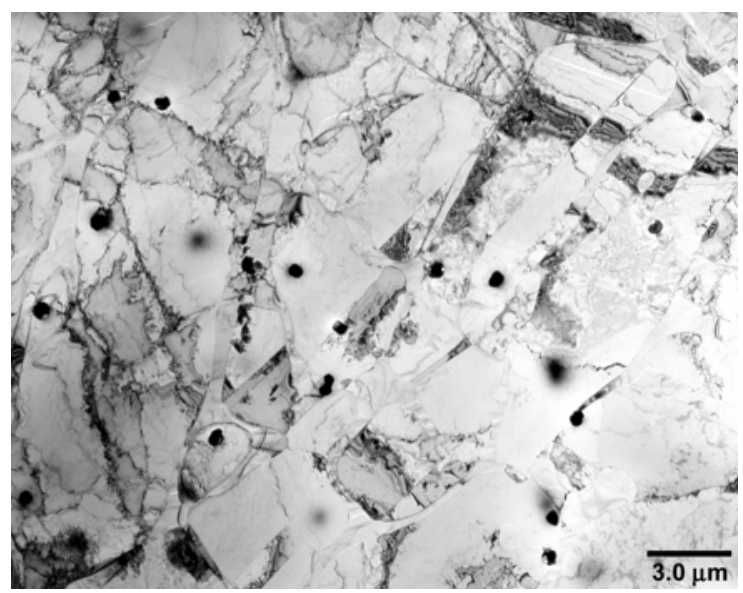

e

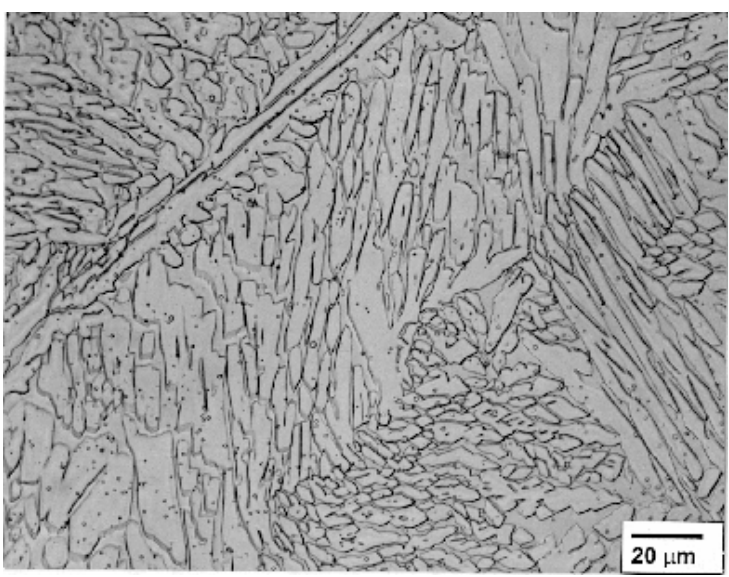

b

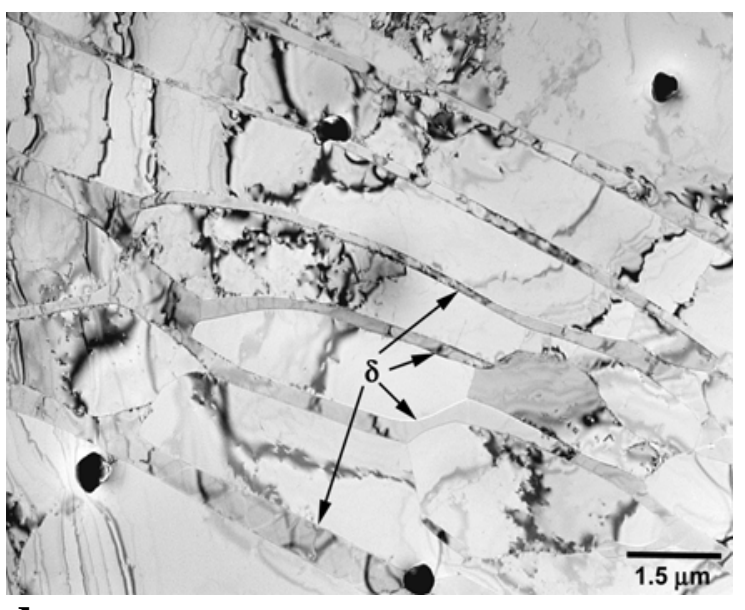

d

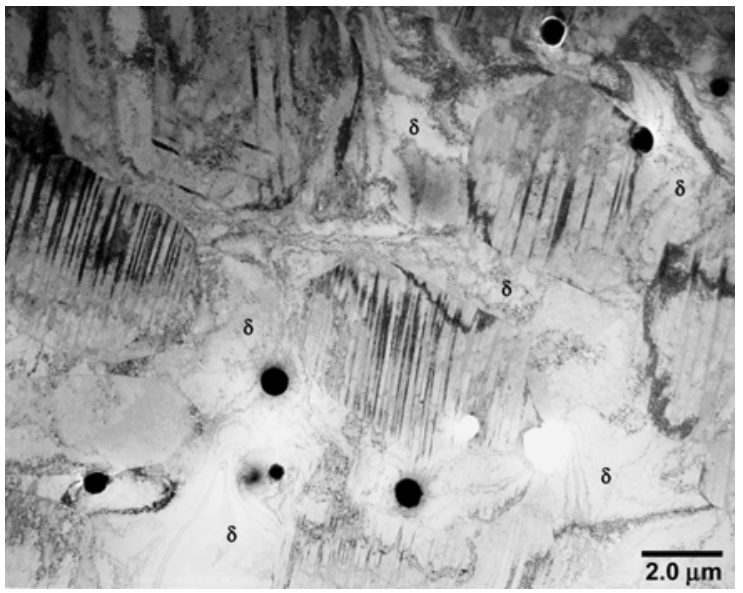

f

Figure 9. Microstructure of the 912 weld - 312 MOD filler wire/21-6-9 conventional forging. (a) and (b) Light-optical images, (c) - (e) TEM images showing cellular and lathy, $\delta$ ferrite, and (f) Deformation twinning in the austenite. Oxide inclusions are visible in (e) and (f). 


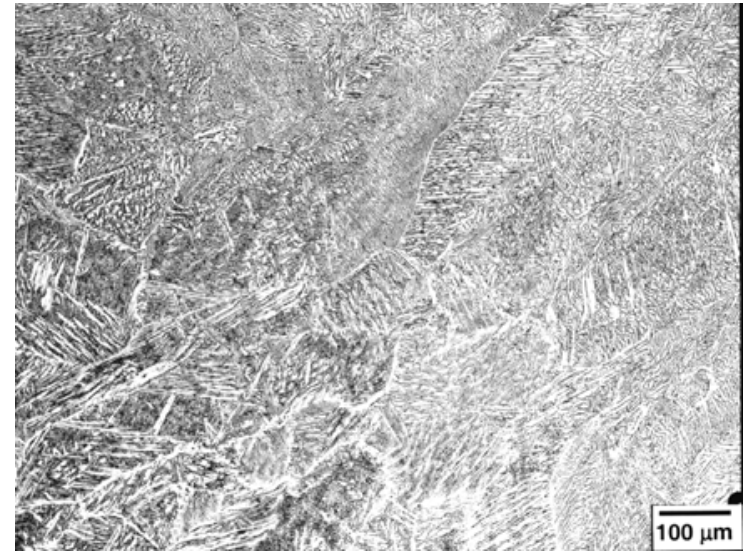

a

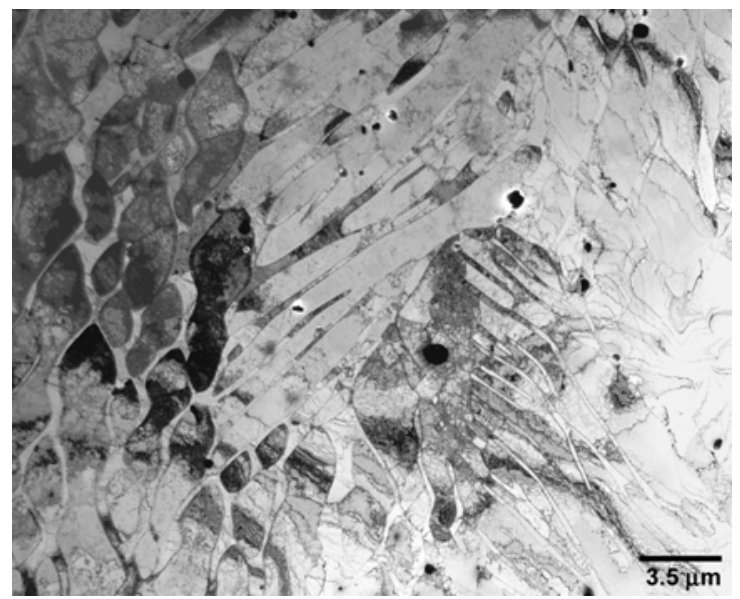

C

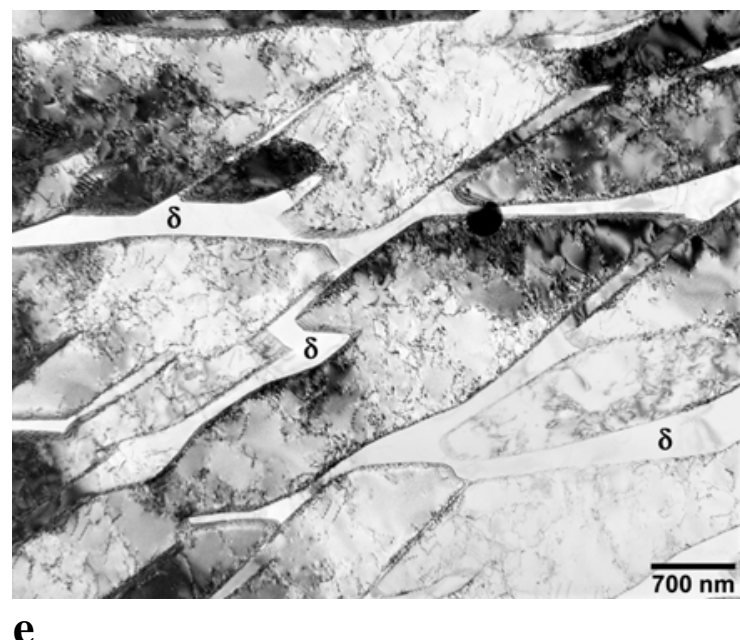

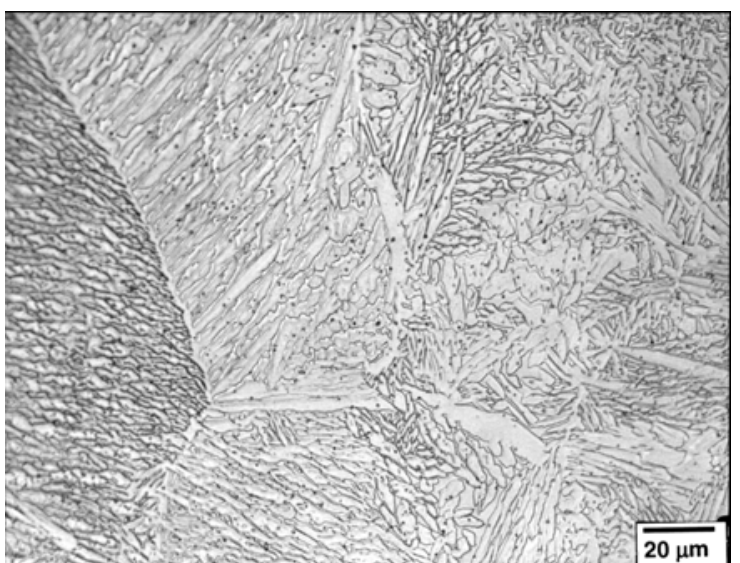

b

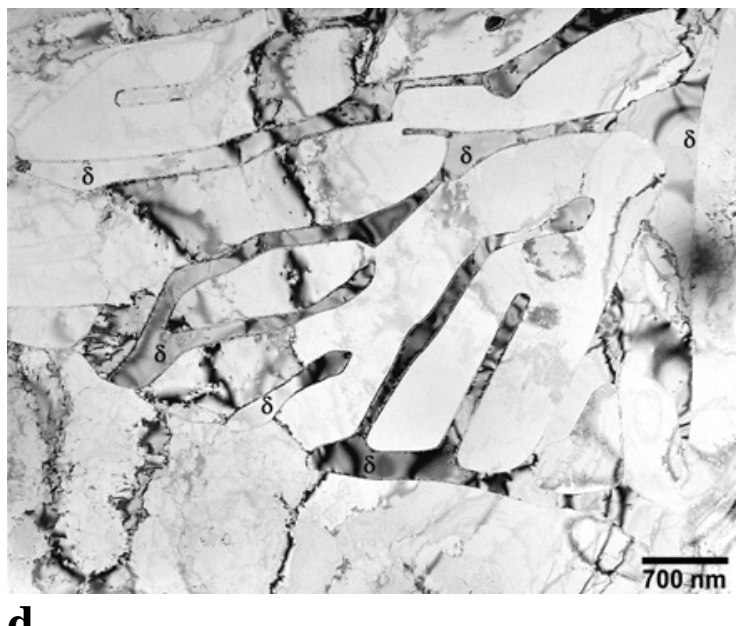

d

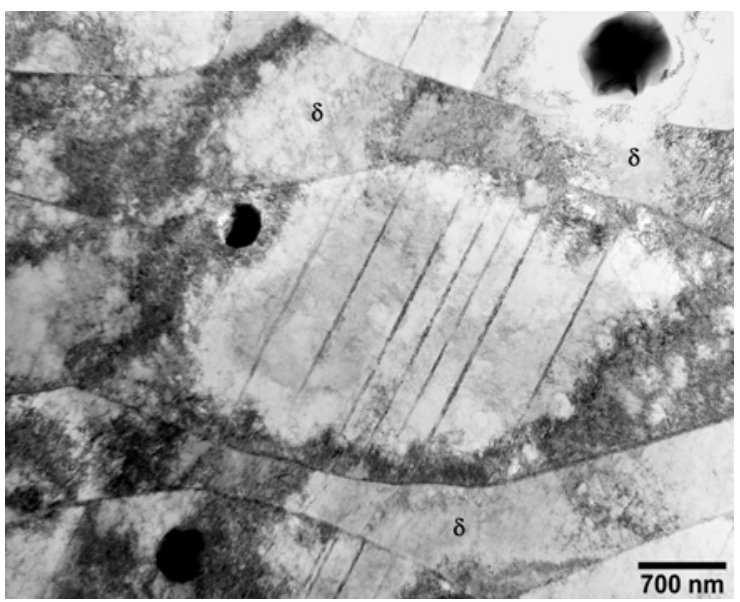

f

Figure 10. Microstructure of the 412 weld - 312 MOD filler wire/304L HERF forging. (a) and (b) Light-optical images, (c) - (e) ferrite/austenite morphologies, and (f) deformation twinning in an austenite grain surrounded by ferrite. 


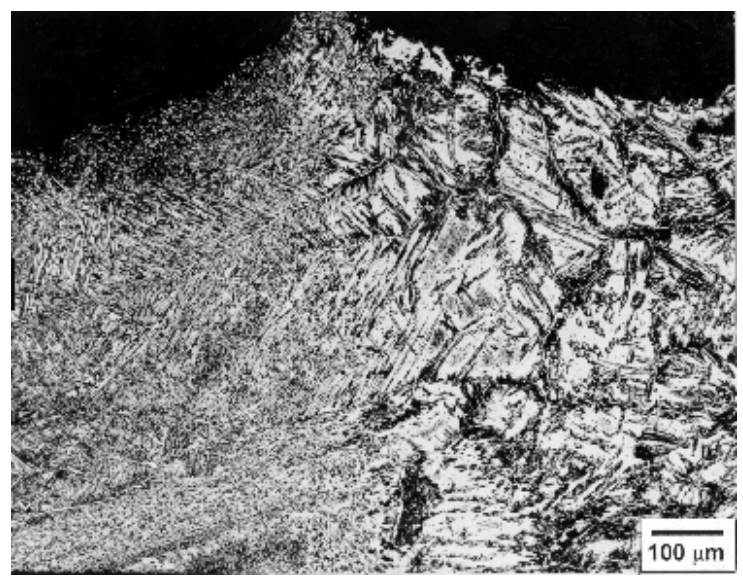

a

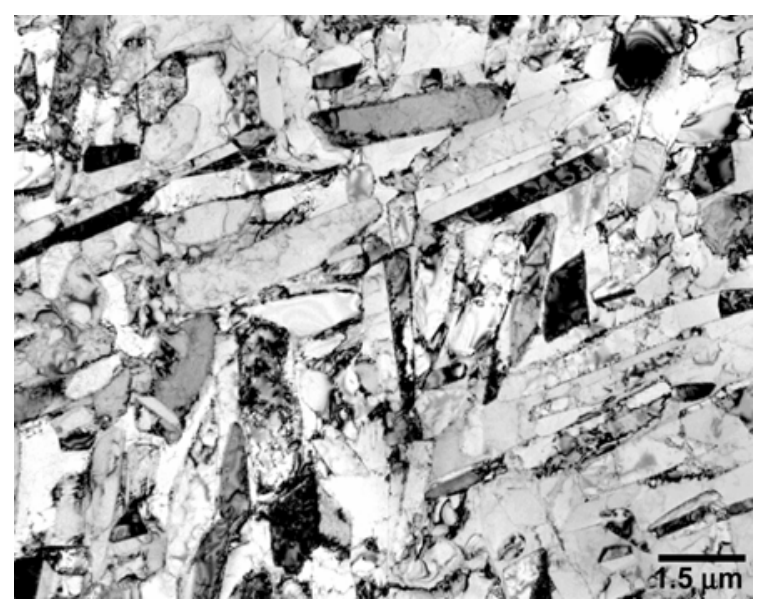

C

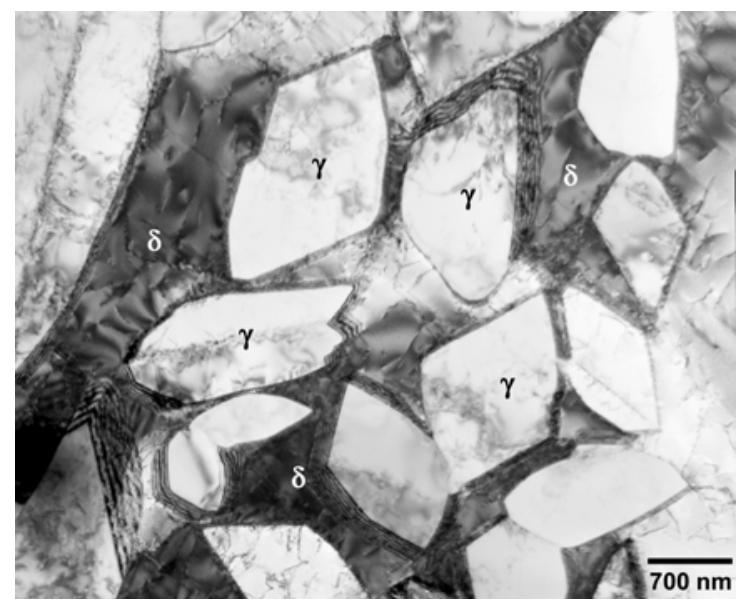

e

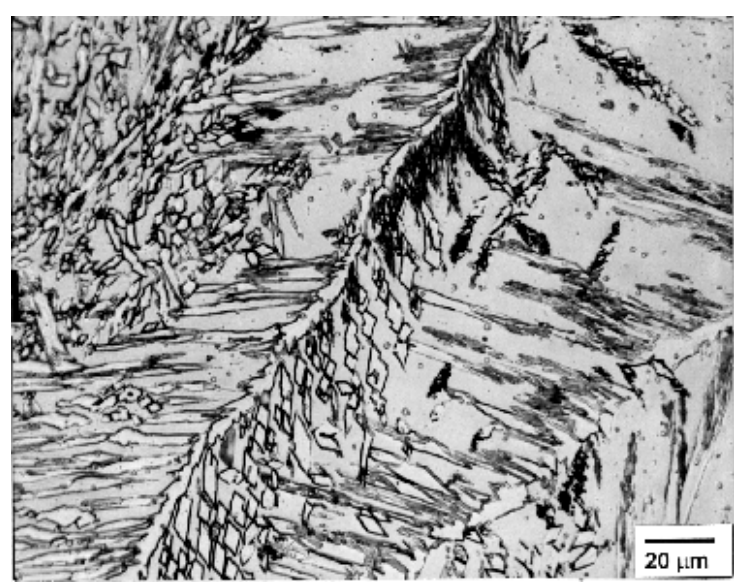

b

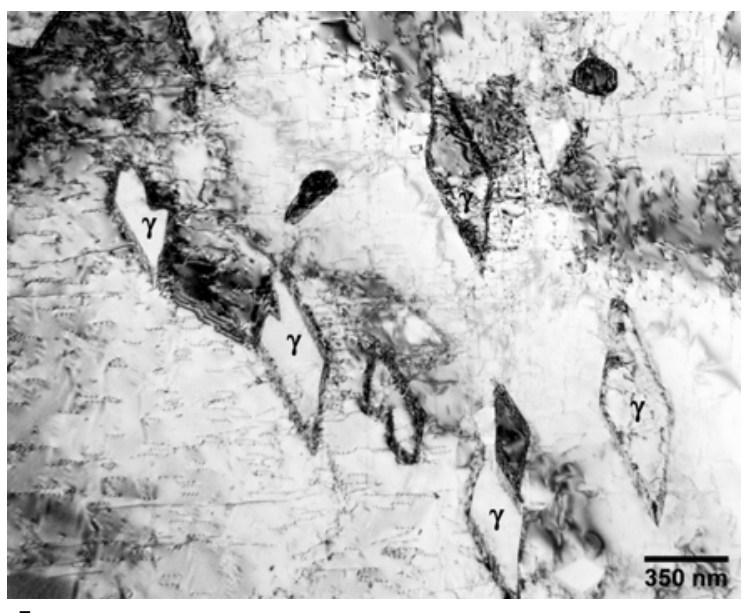

d

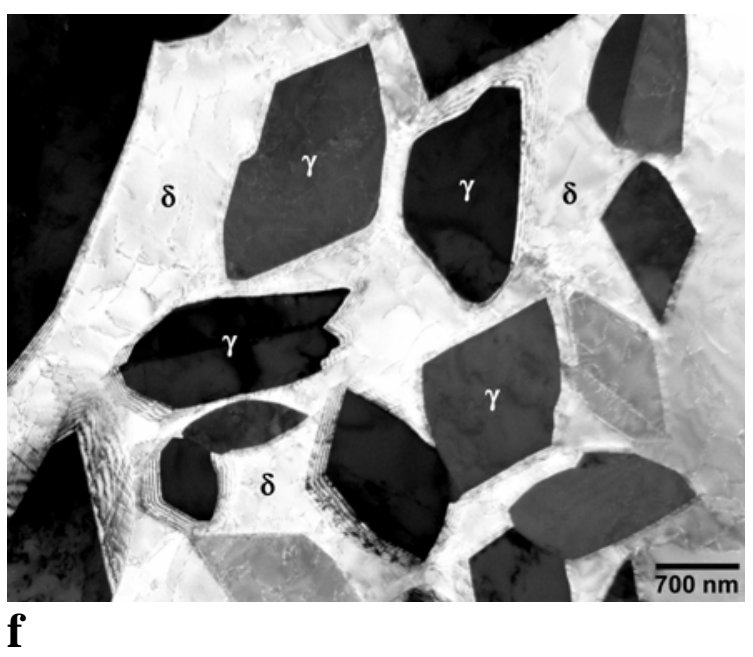

Figure 11. Microstructure of the 49 weld - 309L MOD filler wire/304L HERF forging. (a) and (b) Light-optical images, (c) Widmanstätten austenite, and (d) -(h) ferrite/austenite morphologies. See the text for discussion. 
Figure 11 continued

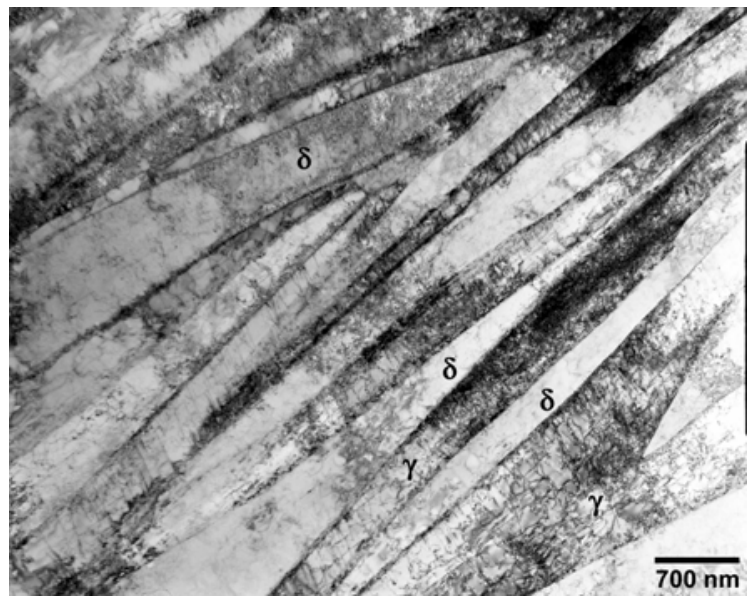

g

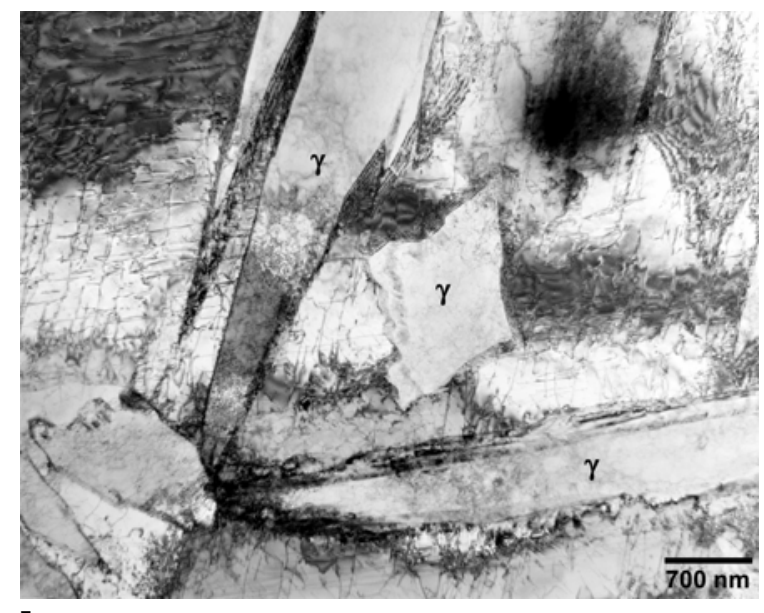

h 


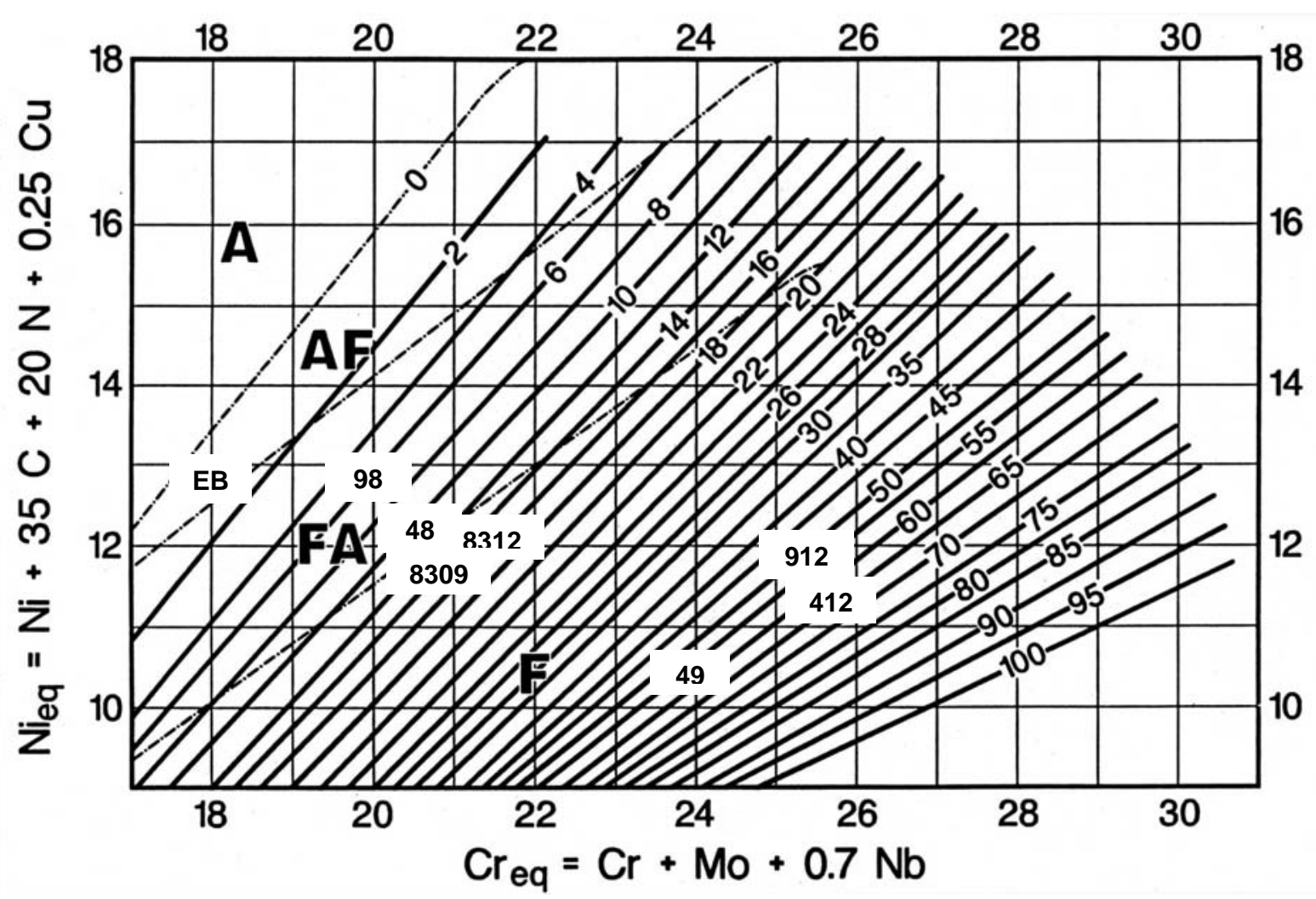

Figure 12. The WRC-1992 diagram [Ref. 6]. The $\mathrm{Cr}_{\text {eq }} / \mathrm{Ni}_{\mathrm{eq}}$ ratios of each weld in the current study are plotted on the diagram. See Table 2 for sample identification nomenclature. 